\title{
How Did the 'Dualization' of the Spanish Income Tax Affect Horizontal Equity? Assessing its Impact Using Copula Functions*
}

\author{
CARLOS DÍAZ-CARO** \\ Universidad de Extremadura \\ JORGE ONRUBIA*** \\ Instituto Complutense de Estudios Internacionales \\ (ICEI, UCM), FEDEA and GEN
}

Received: March, 2018

Accepted: May, 2019

\begin{abstract}
The aim of this paper is to assess horizontal inequity (HI) caused by the introduction of a (semi-) dual structure for the Spanish personal income tax (PIT), adopting a copula function-based measurement framework. Following B $\varnothing$ et al. (2012), we estimate the Clayton, Frank and Gumbel copulas, belonging to the Archimedean class, to quantify the impact of the 2007 Spanish PIT reform on HI, comparing it with the previous tax design applied in 2006. In order to identify possible anticipation and adaptation effects, the analysis covers the 2004-2010 period. This research employs microdata from the Spanish PIT Return Panel. Results reveal two effects of the reform on the HI working in opposite directions: while the partition of the taxable income into two bases (one is taxed at flat rate) increases the HI, the transformation of personal and family allowances into tax credits reduces it. The predominance of one effect over the other depends on the equivalence scale applied.
\end{abstract}

Keywords: dual income tax, Spanish PIT, horizontal equity, copula functions, reranking.

JEL Classification: D31, D63, H31

\footnotetext{
* Acknowledgemens: Earlier versions of this paper were presented at the XVII Spanish Applied Economics Meeting (Las Palmas de Gran Canaria, Spain, June 5-6, 2014), AECID-CEF Seminar on Microsimulation and Taxation (Montevideo, Uruguay, November 13-14, 2014), and at the XXII Spanish Meeting on Public Economics (Santander, Spain, February 5-6, 2015). We gratefully acknowledge the useful comments and suggestions received from referees and editor, Julio López-Laborda, Fidel Picos, A. Jesús Sánchez-Fuentes, and the participants in the abovementioned meetings. We would also like to thank Andoni Montes for his valuable comments and suggestions after a careful reading of the manuscript. All the remaining errors are entirely our responsibility. Onrubia acknowledges the financial support of Spanish Ministry of Science, Innovation and Universities (before Ministry of Economy and Competitiveness), Project ECO2016-76506-C4-3-R, and Díaz-Caro acknowledges the financial support of Spanish Ministry of Economy and Competitiveness (Project ECO2014-53702-P).

** ORCID: 0000-0003-1251-6699. University of Extremadura, Faculty of Business, Finance and Tourism, Department of Applied Economics, Av. de la Universidad s/n, 10071 Cáceres, Spain. e-mail (carlosdc@ unex.es).

*** ORCID: 0000-0001-8394-7387. Instituto Complutense de Estudios Internacionales (ICEI, UCM), FEDEA and GEN. Finca Mas Ferré, Campus de Somosaguas, E-28223, Pozuelo de Alarcón, Madrid, Spain (jorge.onrubia@ ccee.ucm.es). Corresponding author.
} 


\section{Introduction}

Inspired by Nordic tax reforms in the early nineties, the vast majority of developed countries (and many developing countries) have gradually replaced their "synthetic" personal income taxes (PIT) with others with an explicit dual structure. The "pure" (or Nordic) version of dual income tax (DIT) represents a particular approach to achieve a compromise between labour and capital income taxation by means of two differentiated tax bases (Boadway, 2004). In a DIT design, labour income is taxed according to a progressive schedule, while capital income is taxed at a uniform proportional rate equal to the lowest marginal tax rate on labour income ${ }^{1}$. DIT was created in the Nordic countries in the early 1990s. Although Denmark abandoned the system in 1994, in 1987 it became the first country to apply it, followed by Sweden in 1991, Norway in 1992 and Finland in 1993. Since then, many countries have implemented tax reforms adopting a DIT, more or less akin to the pure model. Some examples are Belgium (1993), Austria (1994), The Netherlands (2001), Germany (2002) or Spain $(2007)^{2}$.

Public finance literature states grounds on both efficiency and equity to recommend this dual model. In this regard, the Mirrlees Review considers DIT as a key issue in the current debate on personal income tax reforms (Griffith et al., 2010; and Crawford and Freedman, 2010). Other authors (i.e. Boadway, 2004) add that DIT would discourage fiscal planning or tax avoidance. DIT allows to apply a different progressivity degree on labour and capital income tax bases, this is the source of many of the advantages of this structure. Diamond (2007), based on the theory of optimal taxation, argues that the adaptation of the Atkinson-Stiglitz theorem (Atkinson and Stiglitz, 1976) to an intertemporal utility framework, where present and future consumption are separable from leisure, provides evidence to support that capital income should not be taxed. In this respect, DIT constitutes a reasonable and useful compromise solution between two alternative visions of personal income taxation: comprehensive income taxation, where labour and capital income are taxed at the same marginal tax rates, and personal expenditure taxation, where capital income is not taxed at all (Boadway, 2011) . $^{3}$

Regarding distributive justice, the issue is more complex and has attracted less attention in literature. In terms of vertical equity (VE), progressivity depends not only on the tax rate schedule but also on the share that each base represents on the total tax base, since they are respectively progressively and proportionally taxed (Lambert and Thoresen, 2012; LópezLaborda, 2006). For Spanish personal income tax (IRPF in its Spanish acronym), Díaz-Caro et al. (2013) showed that the dual model that came into force in 2007 resulted in a notable increase in global progressivity (3.8 per cent) compared with the previous model applied in 2006. Apart from the introduction of a flat tax rate for savings income and capital gains from asset transfers (in addition to the progressive schedule applied to the remaining incomes), this reform also included changes to the treatment of personal and familiar circumstances, where allowances were converted into tax credits ${ }^{4}$.

Focusing on horizontal equity (HE), the introduction of DIT would be at odds with the traditional principle of taxation with respect to the equal treatment of equals, initially gua- 
ranteed by the comprehensive taxation approach. It is well known that HE is typically considered a pacific principle in tax system design (Shoup, 1969), although it has been found to be far from being widespread in the real world of comparative tax systems ${ }^{5}$. However, we think that $\mathrm{HE}$ is one of the most important commands of tax design. HE is especially relevant for tax evaluation, not only because of its indisputable effects on distributive justice, but also due to its implications on voluntary tax compliance and tax morale as a whole ${ }^{6}$. Therefore, the achievement of HE should be considered as one of the key objectives to take into account when designing PIT. Likewise, as suggested by Auerbach and Hassett (2002) and Dardanoni and Lambert (2001), the relevance of HE from an academic point of view should be at the heart of the public and political debate on tax reform processes.

Consequently, we think it is worth analysing how DIT may influence HE insofar as both components of the ability to pay are taxed at different intensity. Furthermore, as Sørensen (1994:73) notes, the biggest problem associated with DIT is the incentive to shift income between the two tax bases ${ }^{7}$. This problem leads to greater HI, since taxpayers with the same income could be taxed differently depending on their real tax planning and avoidance opportunities.

In order to accurately measure HI in DIT, we first need to have a clear and precise definition of the meaning of HI within PIT. But literature has not yet reached a consensus on this point. In fact, it is common to find different definitions and interpretations of the HE depending on whether it is a theoretical or quantitative approach. In our opinion, using a consistent measurement methodology that includes the key aspects laying behind the conventional notion of HE, namely, the equal treatment of equals, is the best way to successfully overcome these clashing interpretations.

In this sense, Dardanoni and Lambert (2001) (DL hereinafter) argue for an attractive concept of HE measurement based on the intensity of unequal tax treatment, a key issue not incorporated in the traditional approaches based on classical notion of the similar treatment or on the reranking produced.

The aim of this paper is to compare the HI caused by the introduction in Spain, in 2007, of a (semi-) dual income tax system, with the HI generated by the previous design applied until 2006, closer to a synthetic income tax system. For this purpose, we adopt the copulafunctions-based framework proposed by DL (2001) to measure HI, but using the parametric approach proposed by B $\emptyset$ et al. (2012) to estimate Clayton, Frank and Gumbel copulas, belonging to the Archimedean class. In order to identify possible tax reform's anticipation and adaptation effects, our analysis is spread over the period 2004 to 2010 . For the empirical analysis, microdata from the Spanish Personal Income Tax Return Panel (disseminated by the Spanish Institute of Fiscal Studies, IEF) has been used.

The paper is organized as follows. Section 2 describes the different treatments afforded by the Spanish DIT to diverse sources of income, focusing on their foreseeable impact upon HI. Section 3 outlines the theoretical framework adopted, including the copula functions 
estimation methodology, as well as the $\mathrm{HI}$ indices derived from them. Section 4 describes the micro database used and reports the results obtained from empirical analysis. Section 5 concludes the paper.

\section{Spanish dual income tax and horizontal equity}

Given its structure with two different tax schedules -usually, a flat rate for capital income and a progressive schedule for labour income-, the use of DIT structure cannot be expected to lead to perfect HE. Moreover, the possibility of shifting capital income from labour income for tax planning purposes, and the ensuing behavioural reactions, would also have a negative impact on HE. Nevertheless, these authors suggest that these distortions may not have such a substantial effect upon HE. Even so, we should not overlook the implications of tax avoidance and evasion for HE, despite the fact that their impact is not always easy to measure.

The tax reform passed in 2006 (Law 35/2006, in force 2007) represents a clear commitment to adopt a dual structure for the Spanish PIT, although, as explained below, it was not a pure dual system, if we take into account all the characteristics that were usually present in the dual tax designs of the 1990s in the Nordic countries. Following the commonly used terminology, we can refer to it as a semi-dual income tax ${ }^{8}$. We can affirm that this has been the most important reform experienced by the income tax, at least since the Law 40/1998 (in force since 1999) was passed, when most personal and family tax credits were converted into tax allowances.

Accordingly, Spanish PIT levied since 2007 contains two different tax bases: the socalled "general base" taxed applying a progressive schedule; and the so-called "savings base" originally taxed at a flat rate of $18 \% \%^{9}$. Notice, however, that until 2006, Spanish PIT was not, strictly speaking, a "synthetic" PIT, inasmuch as the net capital gains from assets held for a period longer than one year were taxed separately at a proportional rate of $15 \%{ }^{10}$.

Worthy of note, as we have said, is the fact the income segmentation in both bases does not correspond to a strict separation by labour and capital sources, as is the case with the "pure" DIT model. In this respect, the savings tax base of the 2007 Spanish PIT does not include all capital incomes. Specifically, the general tax base includes non-financial capital income, income from real estate and capital gains from competitions, games and gambling, together with labour income and business and professional income. Besides, this reform introduced an exemption of 1,500 euro for dividends, whereas it did away with the dividend imputation with tax credit-imputation system in force since 1995.

Along with non-financial capital and real estate incomes not included in the savings base, the other most relevant difference related to the composition of the two taxable 
bases is the treatment given to self-employed and non-corporate business activities incomes. According to their mixed nature, in "pure" dual system, these incomes are divided into two components: the wage compensation of self-employed; and the entrepreneur or professional investment return. Instead, in Spanish IRPF of 2007, both components are fully included in the general base, without any distinction, and therefore taxed progressively. It should also be noted that self-employed or small business owners have the option of calculating the taxable profit of their activity by means of a modulebased objective estimation system, which leads to include in the taxable base an amount that is generally lower than the one which would have been included if direct assessment based on accounting had been chosen. Although the integration of these mixed income in the general tax base would, in principle, mitigate HI, the underestimation of taxable income caused by the application of the aforementioned objective estimation method is expected to operate in the opposite direction. However, this option was already in force before the reform.

Although not related to the adoption of the dual system, the transformation of most personal and family allowances into non-refundable tax credits, returning to the pre-1999 PIT model, is another tax reform's relevant aspect for our HI analysis. Although defined as allowances in the new tax code, since 2007 they actually work like tax credits, inasmuch as they are calculated by applying the general tax schedule to cumulative amounts known as "personal and family minimums". Despite the progressivity of this schedule, the breadth of the first bracket assures the application of the lowest marginal tax rate for almost all taxpayers ${ }^{11}$. Regarding the previous PIT, this change will lead to decreased HI, insofar as the previous application to the base of the personal and family exemptions was more beneficial for high-income taxpayers, whereas almost all taxpayers will obtain the same tax savings after the reform ${ }^{12}$.

Tables 1 and 2 outline the designs of Spanish PIT for 2006 and 2007, the years before and after the DIT reform.

It is likely that all these changes to the configuration of Spanish PIT led to a reorganization of the general and savings tax bases for income taxpayers, with the consequent impact on tax liabilities. For example, the source of income results in different tax burdens depending on the income category (labour earnings, business profits, rents, financial revenues or capital gains) and their respective tax treatment. In principle, this violates the HE principle, insofar as two taxpayers with the same income but different income compositions face different tax burdens, despite having both the same ability to pay. Note also that it provides incentives for taxpayers to move their income around between categories in order to reduce their tax bills. However, not all taxpayers will have the same tax planning opportunities. This will depend on whether the taxpayer has income-generating options. Thus, it would appear to be easier for self-employed, investors and even top executives than for wage earners, as the results obtained by López-Laborda et al. (2018) corroborate. Of course, such behavioural changes induced by asymmetric tax treatment will also have an impact on HI. 
Table 1

STRUCTURE OF SPANISH PIT (2006 AND 2007)

\begin{tabular}{|c|c|c|}
\hline Concepts & 2006 Spanish PIT & 2007 Spanish PIT \\
\hline $\begin{array}{l}\text { Computation of gross } \\
\text { income }\end{array}$ & \multicolumn{2}{|c|}{$\begin{array}{l}\text { Different types of incomes: labour income, income from savings, self- } \\
\text { employment income and business income, received compensatory pensions } \\
\text { to ex-spouses, rental income, imputed income for non-rented houses, } \\
\text { income attributions, and capital gains and losses }\end{array}$} \\
\hline $\begin{array}{l}\text { Reductions (applied for } \\
\text { calculating incomes) }\end{array}$ & $\begin{array}{l}\text { Rental income deduction and } \\
\text { irregular incomes reduction }\end{array}$ & $\begin{array}{l}\text { Earned income deduction, rental } \\
\text { income deduction and irregular } \\
\text { incomes reduction }\end{array}$ \\
\hline \multirow[t]{2}{*}{$\begin{array}{l}\text { Income classification } \\
\text { (applied for calculating } \\
\text { adjusted gross income and } \\
\text { taxable income) }\end{array}$} & $\begin{array}{l}\text { General part: Labour income, } \\
\text { income from savings, self- } \\
\text { employment income, compensatory } \\
\text { pensions to ex-spouses, rental } \\
\text { income, imputed income for non- } \\
\text { rented houses, income attributions, } \\
\text { and capital gains and losses } \leq 1 \text { year }\end{array}$ & $\begin{array}{l}\text { General part: Labour income, self- } \\
\text { employment income, compensatory } \\
\text { pensions to ex-spouses, rental } \\
\text { income, imputed income for non- } \\
\text { rented houses, income attributions, } \\
\text { and capital gains and losses }\end{array}$ \\
\hline & $\begin{array}{l}\text { Special part: Capital gains and } \\
\text { losses }>1 \text { year }\end{array}$ & $\begin{array}{l}\text { Savings part: Income from savings, } \\
\text { and capital gains and losses }\end{array}$ \\
\hline Adjusted gross income & $\begin{array}{c}\text { Sum of incomes minus personal and } \\
\text { descendant allowances }\end{array}$ & Sum of incomes \\
\hline Taxable income & $\begin{array}{l}\text { Adjusted gross income minus } \\
\text { earned income deduction, } \\
\text { ascendant, age and disability } \\
\text { allowances, compensatory pensions } \\
\text { paid to ex-spouses and pension } \\
\text { schemes allowances } \\
\end{array}$ & $\begin{array}{l}\text { Taxable income minus allowances } \\
\text { for joint taxation, compensatory } \\
\text { pensions paid to ex-spouses and } \\
\text { pension schemes allowances }\end{array}$ \\
\hline \multirow[t]{2}{*}{ Gross tax liability } & $\begin{array}{l}\text { Results of applying respectively the } \\
\text { general and special schedule to } \\
\text { general and special taxable income }\end{array}$ & $\begin{array}{l}\text { Results of applying respectively the } \\
\text { general and savings schedule to the } \\
\text { general and savings taxable income, } \\
\text { minus the result of applying tax } \\
\text { schedules to the sum of personal } \\
\text { and family allowances }\end{array}$ \\
\hline & \multicolumn{2}{|c|}{$\begin{array}{c}\text { The general and special (savings) schedules are divided into state and } \\
\text { regional parts }\end{array}$} \\
\hline Final tax liability & \multicolumn{2}{|c|}{ Gross tax liability minus state and regional tax credits } \\
\hline Refundable tax credits & $\begin{array}{c}\text { For maternity (applying to working } \\
\text { mothers) }\end{array}$ & $\begin{array}{l}\text { For maternity and childbirth } \\
\text { (applying to working mothers) }\end{array}$ \\
\hline
\end{tabular}

Source: Onrubia et al. (2014) and own elaboration. 
Table 2

MAIN PARAMETERS OF THE SPANISH PIT (2006 AND 2007) (EURO)

\begin{tabular}{|c|c|c|}
\hline Concepts & 2006 PIT & 2007 PIT \\
\hline Reduction for irregular incomes & $40 \%$ & $40 \%$ \\
\hline Reduction for earned income & $2,400-3,500$ & $2,600-4,000$ \\
\hline Increment for disability & $+2,800 /+6,200$ & $+2,800 /+6,200$ \\
\hline $\begin{array}{l}\text { Late retirement and geographical } \\
\text { mobility }\end{array}$ & $+100 \%$ for either concept & $+100 \%$ for either concept \\
\hline Rental income deduction (for landlord) & $60 \%$ & $60 \% /-100 \%$ \\
\hline \multicolumn{3}{|l|}{ Personal allowances } \\
\hline General & 3,400 & 5,050 \\
\hline Single-parent family & 5,550 & \\
\hline Joint taxation & 6,800 & \\
\hline Increment for age & $+800 /+1,800$ & $+900 /+2,000$ \\
\hline \multicolumn{3}{|l|}{ Allowance for joint taxation } \\
\hline Single-parent family & & $3,400^{\mathrm{a}}$ \\
\hline Married couples & & $2,150^{\mathrm{a}}$ \\
\hline Descendants allowances & $1,400 / 2,300$ & $1,800 / 4,100$ \\
\hline Increment for age & $+1,200$ per child $<3$ years & $+2,200<3$ years \\
\hline Ascendant allowances & $800 / 1,800$ & $900 / 2,000$ \\
\hline Disability allowances & $2,000 / 7,000$ & $2,270 / 9,170$ \\
\hline $\begin{array}{l}\text { General tax schedules (State }+ \\
\text { Autonomous Community) }\end{array}$ & $15 \%-24 \%-28 \%-37 \%-45 \%$ & $24 \%-28 \%-37 \%-43 \%$ \\
\hline Limits for pension scheme reductions & $8,000 / 24,250$ & $\begin{array}{l}10,000 / 12,500 \\
30 \% / 50 \%(b+c)\end{array}$ \\
\hline Tax rate for special or savings base & $15 \%$ & $18 \%$ \\
\hline Tax credit on housing investment & $15 \% / 25 \%$ & $15 \%$ \\
\hline Tax credit for maternity & $\begin{array}{c}100 \text { per month (from birth to } \\
3 \text { years-old) }\end{array}$ & $\begin{array}{c}100 \text { per month (from birth to } \\
3 \text { years-old) }\end{array}$ \\
\hline Tax credit for childbirth or adoption & - & 2,500 per child \\
\hline
\end{tabular}

Notes: (a) Applied as reduction on taxable income, the rest of the reductions are applicable as tax credits: (b) Net labor income; (c) self-employment income and business income.

Source: Onrubia et al. (2014) and own elaboration.

\section{Theoretical framework}

As Lambert (2001:183) says, "the purpose of the HE command generally is to pursue justice and equality and ensure that the law does not serve anybody's self-interest". Notwithstanding the widespread acceptance of this view of equity, the main problem is how to ensure 
that violation of the HE principle is measured accurately. The literature does indeed offer an extensive list of measures, almost all of which are built on the basis of this undisputable and intuitive idea. It was Feldstein (1976:83) the one who made perhaps the most significant conceptual contribution with respect to measurement, from a welfarist approach: "if two individuals are equally well off (have the same utility level) in the absence of taxation, they should also be equally well off if there is a tax" and then "the introduction of a tax should not alter the ordering of individuals by utility level". Consequently, there should be a perfect positive association between the distributions of pre- and post-tax income. Accordingly, the dissociation between the two distributions would be a sign of HI. However, it is not easy to implement this notion into practice. As Jenkins (1988) warns: "How should differential treatment which has some equity justification be distinguished from that which does not?".

\subsection{Traditional HE approaches}

Initially, Atkinson (1980) and Plotnick (1981) proposed reranking-based measures as a way to identify a non-perfect association between pre- and post-tax income distributions. This "reranking approach" was inspired by the abovementioned concept of EH proposed by Feldstein (1976). Later, King (1983), Cowell (1985) and Jenkins (1988) developed other statistical measures based on the same concept. Since its appearance, the requirement of rank preservation received criticism, since it was easy to find examples of tax treatments considered as horizontally unfair that did not cause reranking, and vice versa (Jenkins and Lambert, 1999).

The "classical" similarity-based definition of HE underlies the second approach. Thus, PIT meets the HE criterion if "taxes bear similarly upon all people in similar circumstances" (Simons, 1950) or, alternatively, "all taxpayers in equal positions are treated equally" regarding income distribution (Kaplow, 1989). According to this approach, HI measurement involves singling out the variability existing across tax liabilities of individuals who have similar pre-tax incomes. Berliant and Strauss (1983), Aronson et al. (1994), Lambert and Ramos (1997a,b) and Duclos and Lambert (2000) made the most outstanding contributions to this classical approach ${ }^{13}$.

Duclos et al. (2003) proposed an interesting alternative whose conceptual framework integrates the above two -reranking and classical- approaches. Its measures combine reranking indices to identify groups with similar levels of income. These measures are defined and calculated using both parametric and non-parametric techniques.

However, neither of these two approaches is exempt from criticism. The approach of measuring HI by altering the reranking will not work if, despite changes to the utility of similar individuals, there is no after-tax income reranking. Meanwhile the interpretation of the classical approach espousing the equal treatment of similar individuals may also be troublesome. This is especially applicable if the dispersion of average effective tax rates is not 
sufficient to conclude that there is unequal treatment, even if reranking does take place. Another common criticism of this approach is that the determination of the criteria for similarity is subjective. In this regard, the adoption of non-parametric methods (like kernel-based techniques) for similar-partition group selection can be considered as a possible solution to the alternative of establishing ad hoc income brackets, although it lacks a sound economic $\operatorname{argument}^{14}$.

In Spain, different measures from the above approaches have been applied to analyse earlier Spanish personal income tax designs applied during the 1980s and 1990s. Worthy of note are papers by Camarero et al. (1993), Pazos et al. (1995), Moreno (1996), Perrote (2007) and Gallego et al. (2012).

\subsection{Measuring HI through copula functions}

DL (2001) identify the vertical equity of a tax system (VE) with the progressivity that would be necessary to achieve a certain income distribution, whilst the HE would be the way in which this distribution is reached. In accordance with this view, these authors raise an alternative notion of 'purity' (their italics) in the HI measurement based on the intensity of unequal tax treatment, as they highlight, a key tenet not incorporated neither in the classical notion of the equal treatment to equals, nor in the reranking approach.

Starting from the idea that the income tax system $j$ can be fully defined as the joint distribution of pre- $(x)$ and post-tax income $(y), H_{j}=(x, y): R \times R \rightarrow[0,1]$, which shows the share of tax units having pre- and post-tax incomes less than or equal $x$ and $y$ respectively, DL (2001) identify the HI with the "degree of association" between the standards of life reflected by the pre-tax and post-tax income distributions ${ }^{15}$. According to these authors, a positive association between $x$ and y in $H_{j}$ should be consistent with the preferences of a social decision-maker concerned about social welfare, respecting HE properties related to non-reranking, equal treatment of equals, and intensity of unequal treatment.

The focus of their concept in the measurement of HI, as they point out, "renders it independent of the metric for living standards and also of the tax system's vertical performance". In order to evaluate this new conception of HI, they propose the following two axioms, which should be respected by any measure built according to their notion. Both axioms, apart from being supported by the non-reranking idea, are inspired by the classical notion of HE.

Axiom 1 (DL, 2001): HI is the same in the joint distribution $H(x, y): R \times R \rightarrow[0,1]$ as it is in the joint distribution $H(u(x), u(y))$, being $u(\cdot): R \rightarrow R$ any strictly increasing function.

This first axiom ensures that the definition of $\mathrm{HI}$ is invariant to changes in the units of measurement chosen, including those used to reflect living standards. It must be considered 
that classical measures based on equal treatment (as proposed in Aronson et al., 1994, Lambert and Ramos, 1997b or Duclos and Lambert, 2000) violate this property, since they depend on the pre-tax equals groups initially established. Instead, the transformation $u(\cdot)$ preserves pre-tax groups.

Axiom 2 (DL, 2001): HI is the same in the joint distribution $H(x, y): R \times R \rightarrow[0,1]$ as it is in the joint distribution $H(g(x), I))$, being $g(\cdot): R \rightarrow R$ any strictly increasing function, and I is the identity operator.

This second Axiom guarantees that $\mathrm{HI}$ is invariant to further monotonic transformation of the pre-tax income $(x)$. In this way, it is indifferent if the instrument (any tax or, even, a benefit scheme) evaluated from the HE point of view has a progressive or regressive structure. Thus, DL's HI definition is totally independent of any vertical equity consideration.

Both axioms respect the requirements of "non-reranking" and "equal treatment of equals" that respectively ensure the existence of $\mathrm{HE}$ in the two traditional HI measurement approaches. But, in addition, DL's proposal incorporates, as we anticipated, a new postulate, relevant to measure the degree of $\mathrm{HI}$ : the intensity of unequal treatment.

If both axioms are fulfilled, DL (2001) would state the following theoretical result for any monotonic transformation of $x$ and of $y$, as $v(x)=g(u(x))^{16}$ :

Theorem 1 (DL, 2001): Given Axioms 1 and 2, HI is the same in the joint distribution $H(x, y): R \times R \rightarrow[0,1]$ as it is in the joint distribution $H(v(x), u(x))$, being $v(\cdot): R \rightarrow R$ and $u(\cdot)$ : $R \rightarrow R$ any strictly increasing functions.

This result makes possible to consistently compare the existing HI across $j$ alternative tax designs, whether for the same distribution of income (evaluation of options for a tax reform) or for different income distributions (for two or more fiscal years, countries or subcentral governments). In addition, DL (2001, Theorems 2 and 3) state that it is possible to establish a partial ordering of tax systems by HI, in line with the Atkinson and Bourguignon (1982) stochastic dominance criteria for multi-dimensioned distributions, based on the preference of the social decision-maker for an increasing positive association between $x$ and $y$.

To operationalize this concept of HE both from a theoretical and empirical perspective, DL (2001) argue that comparisons of HI between different taxes should be based on measures derived from a copula function of the joint distribution of pre- and post-tax incomes. The justification for this statement is that the copula fulfils this requirement, since it captures those properties of the joint distribution which are invariant under strictly increasing transformations of the random variables (Schweizer and Wolff, 1981: 882). Precisely, as DL (2001) highlight, this invariance required by axioms 1 and 2 is what allows to ensure a "pure" measurement of HI. Furthermore, another advantage is that setting a joint reference distribution for HI comparisons becomes unnecessary. From an empirical point of view, copulas can be a flexible tool for modelling joint distributions in terms of univariate marginal functions 
and measuring the dependence structure between variables ${ }^{17}$. Next, we will outline the framework of the copula functions used in our empirical analysis.

\subsubsection{A parametric copula-based framework for measuring $\mathrm{HI}$}

Let $H(x, y): R \times R \rightarrow[0,1]$ be the bivariate joint distribution function of pre- and post-tax equivalised incomes (denoted by $x$ and $y$, respectively, such that $x, y \in R$ ), with respective marginal distributions $F(x)$ and $G(y)$. Then by Sklar's theorem (Sklar, 1959) there exists a bivariate copula function $C:[0,1] \times[0,1] \rightarrow[0,1]$ such that ${ }^{18}$,

$$
\forall(x, y) \in \mathbb{R}^{2} \Rightarrow H(x, y)=C(F(x), G(y))
$$

Furthermore, inasmuch as $F(x)$ and $G(y)$ are continuous, $C$ is unique ${ }^{19}$.

Taking into account that by the probability integral transform, data values that are modelled as being random variables from any given continuous distribution can be converted into random variables having a standard uniform distribution $U(0,1)$, there is an implicit copula $C$ for the uniform transformations $u=F(x)$ and $v=G(y)$, defined as a bivariate distribution function with $U(0,1)$ marginals, such that,

$$
\forall(u, v) \in \mathbb{I}^{2} \Rightarrow C(u, v)=H\left(F^{-1}(u), G^{-1}(v)\right)
$$

where $F^{-1}(\cdot)$ and $G^{-1}(\cdot)$ denote the generalized inverse functions of $F(\cdot)$ and $G(\cdot)$ with domains $I=[0,1]$.

As Nelsen (2006) explains, the corollary of Sklar's theorem that is behind Equation (2) allows to establish this relation,

$$
C(F(x), G(y)) \equiv C(u, v)=H(x, y)
$$

Equation (3) is crucial for empirical work with copulas. It is enough to transform the vectors of the values of the variables $x$ and $y$ (in our case the incomes before and after the tax, in equivalent terms) into two uniform distributions $U(0,1)$, and calculate their inverse through marginal functions. Once dependence for resulting variables has been stablished, after projecting them in the $[0,1]$ range, we are finally able to obtain the bivariate copula with the uniform marginals that we are looking for.

Despite the theoretical strengths outlined above, as far as we know, the application of copula functions to tax systems' HI empirical evaluation has not been carried out after a decade since the publication of DL's proposal. Most likely, computational difficulties to estimate copulas from large samples of tax microdata could explain this poor implementation, although this issues should not be too relevant nowadays ${ }^{20}$. From an informational 
point of view, it is important to keep in mind that a copula function is a hidden dependence structure, not directly observable. Therefore, in order to statistically model a copula function, a parametric specification is required. In addition, this explicit specification is necessary to control the strength of dependence. As Nelsen (2003) points out, literature includes a wide collection of copula specifications, generally classified by families, defined according to one or more real parameters, and with different levels of complexity for their estimation. As reviewed in Nelsen (2006) and Trivedi and Zimmer (2005), there are many parametric copula families, which usually include parameters to control the strength of dependence.

Indeed, to measure the degree of $\mathrm{HI}$ in Norway, Bø et al. (2012) propose to carry out parametric estimations of copula functions, which allows to directly obtain dependence measures considered as HI indices, according to the conditions laid down in DL (2001). In particular, they estimate copulas belonging to the Archimedean class, widely used in finance, insurance and risk management. Its popularity is mainly explained by the fact that in most cases they have an explicit formulation, being defined by a single dependence parameter $\theta$. Accordingly, a copula belongs to the Archimedean class if it is of the generic form,

$$
C(F(x), G(y) ; \theta) \equiv C(u, v ; \theta)=\varphi^{[-1]}(\varphi(u ; \theta)+\varphi(v ; \theta) ; \theta)
$$

where $\phi:[0,1] \times \Theta \rightarrow[0, \infty)$ (so-called generator function) is continuous, strictly decreasing and convex, such that $\phi(1 ; \theta)=0$, for $\theta \in \Theta$, and $\phi^{[-1]}$ is its pseudo-inverse, defined by $\phi^{[-1]}(t ; \theta)$ $:\left\{\phi^{-1}(t ; \theta)\right.$ if $0 \leq t \leq \phi(0 ; \theta) \| 0$ if $\left.\phi(0 ; \theta) \leq t \leq \infty\right\}$.

In our analysis for the Spanish dual income tax, we also use copulas belonging to the Archimedean class. This class of copula functions has several advantages for the purpose of our research. First, these copulas can capture a wide range of dependence structures (Genest and Rivest, 1993). Second, they are quite straightforward to generate computationally (Wang and Wells, 2000). Specifically, following the recommendation made by Bø et al. (2012), we also use the well-known Clayton (1978), Frank (1979) and Gumbel (1960) bivariate copulas belonging to the Archimedean family. This selection allows covering the full dependence spectrum, so the Clayton copula accurately reflects the dependence between variables in the left tail, the Frank copula exhibits symmetric dependence in both tails, and, finally, the Gumbel copula captures right tail dependence. In accordance with expression (4), we present below the explicit definitions of these three copulas.

\section{- Clayton copula}

$$
C(u, v ; \theta)=\left(u^{-\theta}+v^{-\theta}-1\right)^{-1 / \theta}
$$

with dependence parameter $\theta \in[-1, \infty) \backslash\{0\}$. Thus, when $\theta$ is close to zero, its respective marginal distributions are independent. The generator of this copula is $\varphi_{\theta}(t)=\frac{1}{\theta}\left(t^{-\theta}-1\right)$, and its inverse, $\phi_{\theta}^{-1}(\mathrm{t})=(1+\theta \mathrm{t})^{-1 / \theta}$. 
The Clayton copula is asymmetric with a strong left tail dependence and a weak right tail dependence. This copula function is appropriate for modelling joint distributions when the correlation of the two variables is higher in the left tail. Unlike the Frank copula, the Clayton copula cannot account for negative dependence.

- Frank copula

$$
C(u, v ; \theta)=-\frac{1}{\theta} \log \left(1+\frac{(\exp (-\theta u)-1)(\exp (-\theta v)-1)}{\exp (-\theta)-1}\right)
$$

with dependence parameter $\theta \in(-\infty, \infty) \backslash\{0\}$, reflecting the symmetry of both tails. The generator of this copula is $\phi_{\theta}(t)=-\log \left(\frac{\exp (-\theta t)-1}{\exp (-\theta)-1}\right)$, and its inverse, $\phi_{\theta}^{-1}(\mathrm{t})=$ $=-\frac{1}{\theta} \log (1+\exp (-t)(\exp (-\theta)-1))$.

Besides, this copula can account for negative dependence. Therefore, it is recommended for modelling joint distributions with a strong positive and negative dependence. A drawback is that the Frank copula tends not to be very good for tail dependence measurement. Indeed, it picks out strong dependence in the middle of the distribution. Hence it is recommended for use with data that exhibit strong central and weak tail dependence.

- Gumbel copula

$$
C(u, v ; \theta)=\exp \left(-\left[(-\ln u)^{\theta}+(-\ln v)^{\theta}\right]^{1 / \theta}\right)
$$

with dependence parameter $\theta \in[1, \infty)$. The generator of this copula is $\phi_{\theta}(t)=(-\log t)^{\theta}$, and its inverse, $\phi_{\theta}^{-1}(t)=\exp \left(-t^{1 / \theta}\right)$.

Like the Clayton copula, the Gumbel copula does not account for negative dependence. Unlike the Clayton copula, however, the Gumbel copula exhibits strong right tail dependence and relatively weak left tail dependence. It is recommended for use when the joint distribution shows a strong correlation at high values and a weaker correlation at low values.

\subsubsection{Measures of dependence}

Concerning the choice of a particular type of copula function, it usually depends on the existing structure of dependence between the two variables considered. According to the definition of copula, any measure aimed at capturing this dependence should just depend on the copula and not on its marginal distributions. Usually, this dependence relation is measured by means of statistical measures of association, such as Kendall's tau $(\tau)$ and Spearman's rho $(\rho)$, which are copula-consistent insofar as both are invariant for increasing transformations of the variables. 
— Kendall's tau $(\tau)$ (Kendall, 1938).

Let $H(x, y)$ be a bivariate continuous joint distribution function of pre- and post-tax equivalised incomes $x$ and $y$, with univariate margins $F(x)$ and $G(y)$, Kendall's tau, expressed in terms of probability, is defined as the probability of concordance minus the probability of discordance for a pair of observations $\left(x_{i}, y_{i}\right)$ and $\left(x_{j}, y_{j}\right)$ chosen randomly from the distribution:

$$
\begin{gathered}
\tau_{x y}=\operatorname{Pr}\left[\left(x_{i}-x_{j}\right)\left(y_{i}-y_{j}\right)>0\right]-\operatorname{Pr}\left[\left(x_{i}-x_{j}\right)\left(y_{i}-y_{j}\right)<0\right]= \\
=2 \operatorname{Pr}\left[\left(x_{i}-x_{j}\right)\left(y_{i}-y_{j}\right)>0\right]-1=4 \int H(x, y) d H(x, y)-1
\end{gathered}
$$

Because $\tau$ is strictly invariant to increasing transformations, (8) can be expressed in terms of the copula associated with $H$ :

$$
\tau=4 \iint_{[0,1]^{2}} C(u, v) d C(u, v)-1
$$

For the three chosen Archimedean copulas -Clayton, Gumbel, Frank-, Kendall's tau is defined as a function of the dependence parameter $\theta$, respectively, such that:

$$
\begin{gathered}
\tau=\frac{\theta}{\theta+2} \\
\tau=\frac{\theta-1}{\theta} \\
\tau=1-\frac{4}{\theta}\left[1-D_{1}(\theta)\right]
\end{gathered}
$$

where $D_{1}$ is the Debye function of order one, $D_{1}=\frac{1}{\theta} \int_{0}^{\theta} \frac{t}{e^{t}-1} d t$.

- Spearman's rho $(\rho)$ (Spearman, 1904).

Let $H(x, y)$ be a bivariate continuous joint distribution function of pre- and post-tax equivalised incomes $x$ and y, with univariate margins $F(x)$ and $G(y)$, Spearman's rho is defined as the correlation of $F(x)$ and $G(y)$. Since $F(x)$ and $G(y)$ are transformable by $U(0,1)$ as random variables, under the assumption of continuity, their expected value are $1 / 2$ and their variance are 1/12. Hence, Spearman's rho is,

$$
\rho=12 \iint_{[0,1]^{2}} F(x) G(y) d H(x, y)-3
$$

Because $\tau$ are invariant to strictly increasing transformations, (13) can be expressed in terms of the copula associated with $H$ :

$$
\rho=12 \iint_{[0,1]^{2}} u v d C(u, v)-3=12 \iint_{[0,1]^{2}} C(u, v) d u d v-3
$$

For Frank copula, Spearman's rho can be defined as a function of the dependence parameter $\theta$, respectively, such that, 


$$
\rho=1-\frac{12}{\theta}\left[D_{1}(\theta)-D_{2}(\theta)\right]
$$

where $D_{k}(\theta)$ is the Debye function of order $k, D_{k}(\theta)=\frac{k}{\theta^{k}} \int_{0}^{\theta} \frac{t^{k}}{e^{t}-1} d t$, for $n$ positive integer. For the Clayton copula, Spearman's rho expression has a rather complex form, whereas for the Gumbel copula there is no closed form.

$\mathrm{B} \emptyset$ et al. (2012) propose the use of the Spearman's rho and of the Kendall's tau, calculated from the estimation of the copulas chosen, to measure HI. Both coefficients capture the "degree of association" between the pre-tax and post-tax incomes distributions, identifying the difference respect to full association with the degree of HI caused by the tax. In this sense, the lack of association reflects the intensity of unequal treatment.

Another usual measure in the dependence analysis is the so-called Blomvquist beta $(\beta)$. Likewise, limiting dependence is commonly measured via the so-called tail-dependence coefficient, distinguishing between lower (left) and upper (right) tail dependence, $\left(\lambda_{L}\right.$ and $\lambda_{U}$, respectively). We also use them in the empirical analysis to complement the previous two.

- Blomqvist's beta $(\beta)$ (Blomqvist, 1950).

Let $H(x, y)$ be a bivariate continuous joint distribution function of pre- and post-tax equivalised incomes $x$ and $y$, with univariate margins $F(x)$ and $G(y)$, and respective medians $\ddot{x}$ and $\ddot{y}$, Blomqvist's beta, also known the medial correlation coefficient, is defined, in terms of probability, as:

$$
\beta_{x y}=\operatorname{Pr}[(\mathbf{x}-\ddot{x})(\mathbf{y}-\ddot{y})>0]-\operatorname{Pr}[(\mathbf{x}-\ddot{x})(\mathbf{y}-\ddot{y})<0]
$$

Blomqvist's beta can easily be expressed in terms of the copula associated with the distribution $H(x, y)$ :

$$
\beta=4 C(u, v)\left(\frac{1}{2}, \frac{1}{2}\right)-1=-1+4 \varphi^{[-1]}\left[2 \varphi\left(\frac{1}{2}\right)\right] ; \beta \in[-1,1]
$$

For Clayton, Gumbel and Frank copulas, Blomqvist's beta can be defined as a function of the dependence parameter $\theta$, respectively, such that:

$$
\begin{gathered}
\beta=4\left(2^{\theta+1}-1\right)^{-1 / \theta} \\
\beta=2^{2-2^{1 / \theta}}-1 \\
\beta=1+\frac{4}{\theta} \ln \left(\frac{1}{2}\left(e^{-\theta / 2}+1\right)\right)
\end{gathered}
$$

- Tail dependence $(\lambda)$

The coefficients of lower (left) and upper (right) tail dependence can be expressed in terms of the copula as: 


$$
\begin{gathered}
\lambda_{L} \in(0,1]=\lim _{u \rightarrow 0} \frac{C(u, u)}{u} \\
\lambda_{U} \in(0,1]=\lim _{u \rightarrow 1} \frac{1-2 u+C(u, u)}{1-u}
\end{gathered}
$$

For the chosen Archimedean copulas, tail dependence shows the following values, expressed in terms of $\theta$ (Caillault and Guegan, 2005): Gumbel, $\lambda_{L}=0, \lambda_{U}=2-2^{\theta}$ (iff $\theta \neq 1$ ); Clayton, $\lambda_{U}=0, \lambda_{L}=2^{-1 / \theta}$ (iff $\theta>0$ ). As we know, the Frank copula exhibits tail independence, so that $\lambda_{L}=\lambda_{U}=0$. Again, their difference with the values of perfect association should be considered a measure of the degree of IH.

According to Bø et al. (2012), the difference with respect to one of these four measures of dependence can be interpreted as indices of $\mathrm{HI}$, which are consistent with the HE approach based on copulas: $1-\tau, 1-\rho, 1-\beta, 1-\lambda_{L}$ or $1-\lambda_{U}$. Thus, there is no HI when the degree of dependence between the uniform distributions of pre- and post-tax income is 1 .

\subsubsection{Criteria for copula selection}

A goodness-of-fit test has to be run to check that the choice of copula function is correct. In order to compare different fitted copulas, the log-likelihood and related measures penalizing large numbers of parameters, such as the Akaike information criterion (AIC) and Bayesian information criterion (BIC), are frequently applied. In the case of the AIC, the penalty only depends on the number of parameters, whereas the BIC also depends on the sample size (Joe, 1997) ${ }^{21}$.

\section{— Akaike Information Criterion (AIC) (Akaike, 1974).}

Let $k$ be the number of parameters estimated in the model and $L$ the maximum value of the likelihood function for the estimated model. Then, the AIC value of the (copula) model is:

$$
A I C=2\left(-\log \mathcal{L}\left(\theta ; y_{1}, y_{2}\right)\right)+2 k
$$

- Bayesian Information Criterion (BIC) (Schwarz, 1978).

Let $k$ be the number of parameters estimated in the (copula) model and $L$ the maximum value of the likelihood function for the estimated model on a sample of size $n$. Then the BIC value of the (copula) model is:

$$
B I C=k \log (n)-2 \log \left(\mathcal{L}\left(\theta ; y_{1}, y_{2}\right)\right)
$$

Under these two comparison criteria, the preferred model will be the one with the lowest value. In our case, as all copula are estimated with the same number of parameters and the 
same sample, it is obvious that the application of these goodness-of-fit tests leads to the choice of the copula with the highest log-likelihood $(L)$ value.

\section{Empirical analysis}

\subsection{Data}

As mentioned in the introduction, our main aim is to evaluate the effects on HE of the adoption in 2007 of a dual model for Spanish PIT using the copula functions approach proposed by Bø et al. (2012). In order to quantify this impact, we compare the HI generated by the new dual PIT with the previous design applied in the year 2006, close to a 'synthetic' income tax system. In order to identify possible tax reform's anticipation and adaptation effects, the analysis is spread over the period 2004 to 2010.

For the empirical analysis, we use microdata from the 1999-2014 Spanish Personal Income Tax Return Panel disseminated by the Spanish Institute of Fiscal Studies (IEF) ${ }^{22}$. This database is an expanded panel that represents the Spanish population of taxpayers who file a PIT return every year. The Spanish Personal Income Tax Return Panel covers what is known as the territory under the common fiscal regime ${ }^{23}$. For each year, the sample includes information from the annual PIT returns submitted by taxpayers, where the different variables correspond with the boxes of the PIT form. These variables are divided into two groups depending on their type: non-monetary variables, which include the main qualitative and personal characteristics of the tax return filers; and monetary variables, which include the amounts (in euros) entered into the PIT form boxes.

From this database, we can reconstruct family tax units for married couples that opted to file their tax returns separately. This concept of family tax unit is equivalent to the concept of tax return for single taxpayers and joint tax return for married taxpayers. In the case of married taxpayers filing separately, however, it involves combining both tax returns ${ }^{24}$. In this regard, we believe that the use of the family tax unit for analysing HI (instead of using the individual tax filer) is a better option for two reasons. First, it allows to take into account possible differentiated tax treatments related to the tax filing option (individual or joint tax return). Second, by adopting this family-based approach, we consider the joint ability to pay of married couples.

To reflect their living standards, the incomes of family tax units are measured weighting the nominal monetary values of their aggregate income using equivalence scales ${ }^{25}$. In particular, three equivalence scales are considered in our analysis: a) "OECD scale" (also called "Oxford scale"), which is defined as $E^{O}\left(n_{1}, n_{2}\right)=1+0.7\left(n_{1}-1\right)+0.5\left(n_{2}\right)$, where $n_{1}$ accounts for the taxpayer's spouse in married couples and the number of ascendants, if any, and $n_{2}$ is the number of dependent descendants; b) "OECD-modified scale", which is defined as $E^{O M}$ $\left(n_{1}, n_{2}\right)=1+0.5\left(n_{1}-1\right)+0.3\left(n_{2}\right)$; and c) "Square root scale", which divides household income 
by the square root of household size, $\left.E^{S R}\left(n_{1}, n_{2}\right)=\sqrt{\left(n_{1}+n_{2}\right.}\right)$. The choice of a specific scale involves accepting a certain value judgment about the differences in needs related to the number and age of tax unit members. If we define "equivalence elasticity" as the response of economic needs to the changes in household size, this elasticity can range from 0 (when unadjusted family income is taken as the income measure) to 1 (when per capita family income is used), with intermediate values $0.73,0.53$ and 0.50 when OECD, OECD-modified and Square Root scales are respectively applied. A smaller value of this elasticity corresponds to a larger economies of scale in the consumption ${ }^{26}$. Of course, these value judgements affect results.

To define gross income, we used the variables contained in the Spanish Personal Income Tax Panel according to the broadest possible criterion of ability to pay. In particular, gross income is calculated for each taxpayer as the sum of all income components included in the general and saving tax bases, to which we add the reductions applied to different sources of income, such as earned-income reduction and housing rent deduction ${ }^{27}$. In respect of taxpayer's net income, it is defined as his or her gross income minus the corresponding tax liability.

\subsection{Results}

This section presents the main results for HI measurement obtained following the theoretical framework explained in the section above. Regarding the estimation of Archimedean copulas, it should be noted that the respective $\theta$ parameters have been estimated by maximum likelihood method using CD-Vine R package (Hofert et al., 2018a,b). Likewise, all the statistics of the estimates and the dependence measures associated to each copula have been computed with this package.

For each of the three equivalence scales considered, Tables 3 to 5 show respectively the estimation results for the Clayton, Gumbel and Frank Archimedean copulas corresponding to 2004 - 2010 period. For each copula, the table contains the value of parameter $\theta$, the loglikelihood value of the estimation $(L)$, and the standard errors of the estimate. From the $L$ values, we compute both the Akaike (AIC) and Bayesian (BIC) information criteria. Finally, values for Kendall's tau independence test are also offered.

In all cases, the estimated values of $\theta$ are significant, being the value of $L$ very high for each type of estimated copula function. Meanwhile, computed values for AIC and BIC show that the Clayton copula is the one which best captures the dependence between the pre- and post-tax equivalised incomes when the OECD and OECD-modified scales are applied, followed by the Gumbel and Frank copulas, in this order. However, when the square root scale is applied, we conclude that the best options for the years 2004, 2005 and 2006 are Gumbel and Frank copulas, in this order. To sum up, except for those three years prior to the tax reform, when we apply the equivalence scale that recognizes greater economies of scale, the 


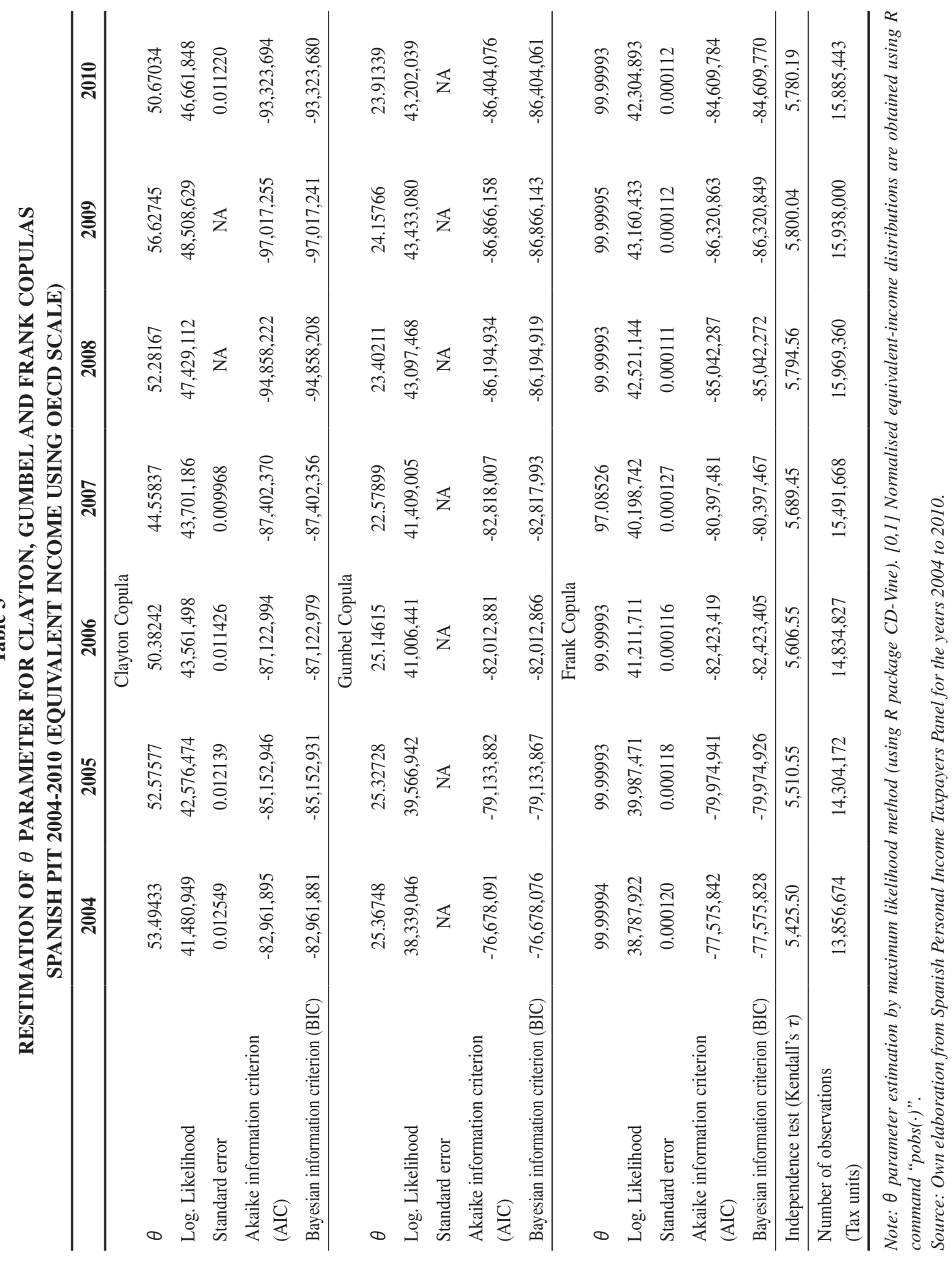




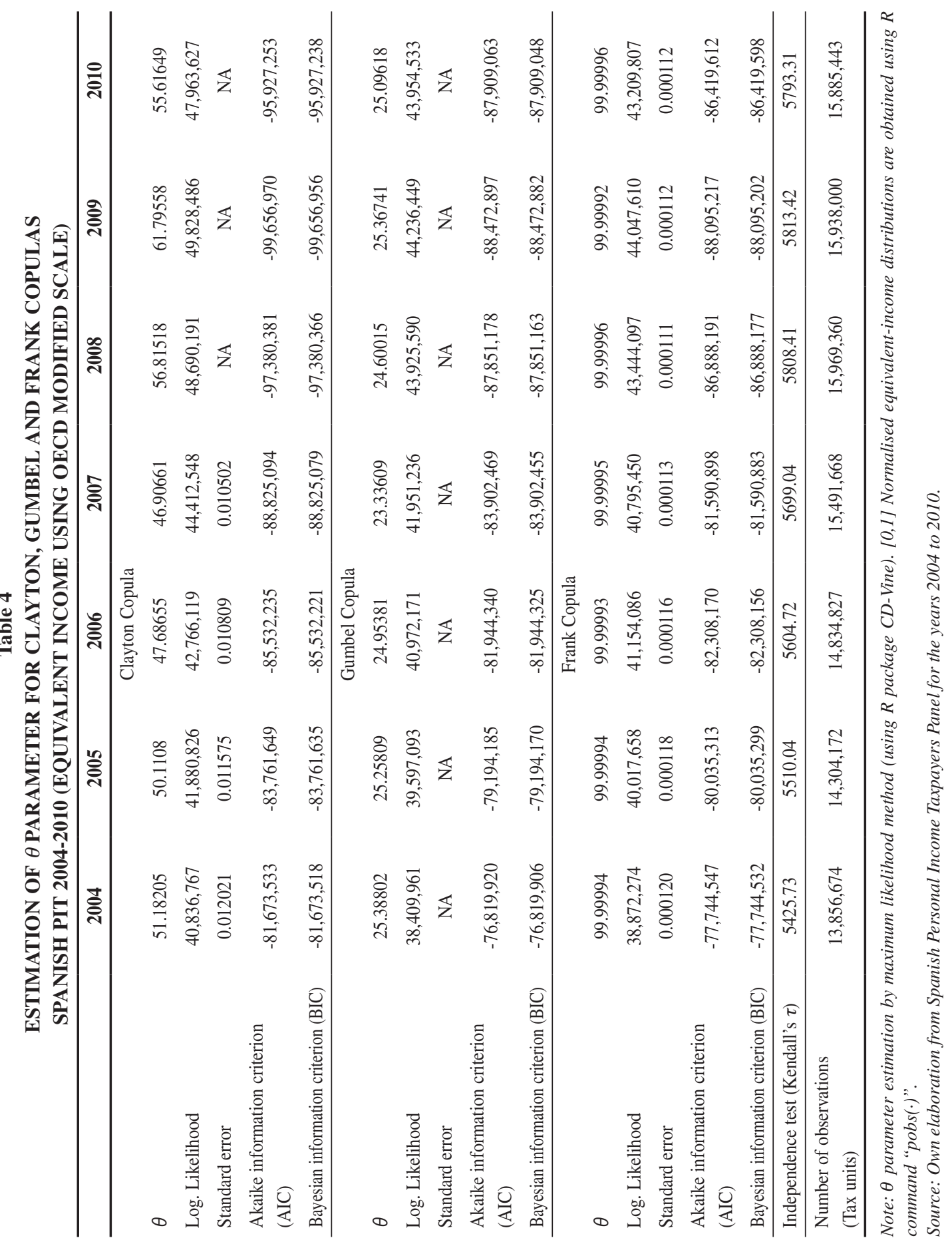




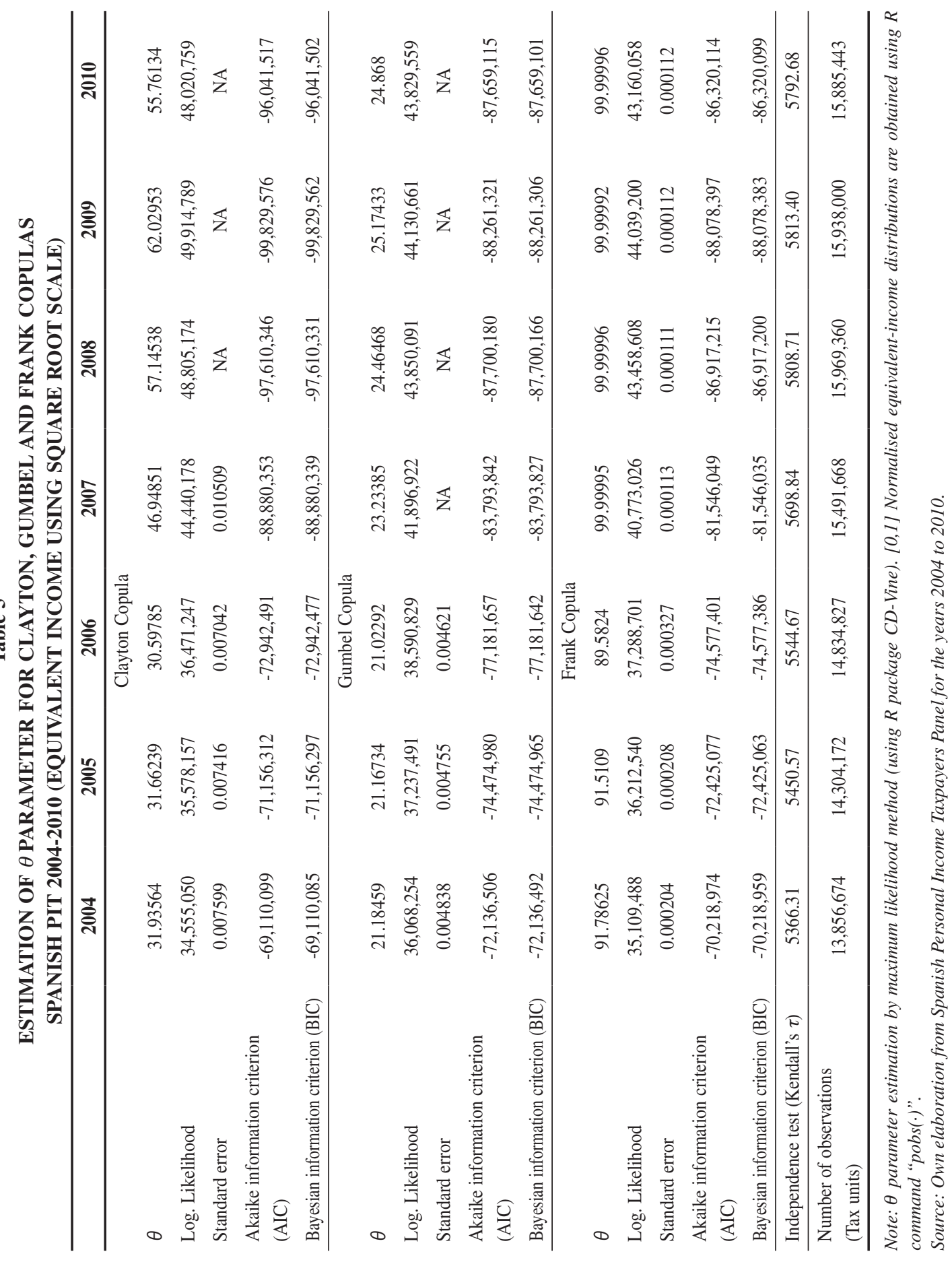


Clayton copula is the best alternative to represent the dependence relationship between the before and after-tax incomes, while the Copula Frank, as almost always occurs, is the one that offers the worst fit to the data. As explained in the methodological section, Clayton copula exhibits left tail dependence (for low incomes), whereas it is weaker in the right tail (for high incomes). As is well known, Frank copula does not show tail dependence in its limits, which explains the fitting problems for the data corresponding to the two variables considered.

Given the typical shape of the before-PIT income distribution, characterized by a greater density at the lower part of the distribution and a high right-skewness, the higher loglikelihood values obtained for the Clayton copula are a foreseeable result. The exception for years 2004, 2005 and 2006, when we applied the square root scale, can be explained by the strong transformation of the pre- and post-tax income distributions induced by that scale of equivalence. In relation to this, we should not forget that the PIT liabilities are calculated by applying the tax rates on taxable bases expressed in monetary terms.

Values for HI indices based on copula dependence measures $\left(1-\tau, 1-\rho, 1-\beta, 1-\lambda_{L}\right.$ or $1-$ $\lambda_{U}$ ), for each of the three equivalence scales considered, are respectively reported in Tables 6 to 8 . Their evolution between 2004 and 2010 is graphically shown in the panels included in Figures 1 to 3. In each of these Figures, upper panels plot the results obtained for the Clayton copula, middle panels for the Gumbel copula and the lower panels for the Frank copula. In particular, left panels display values for $1-\tau$ on the left axis, and for $1-\rho$ on the right axis, while right panels display values for $1-\beta$ on the left axis, and for $1-\lambda_{L}, \lambda_{U}$ on the right axis. In view of the results, we can anticipate that, in each scenario, the four measures calculated behave in a similar way, as expected.

If we focus on the results for the Clayton copula when pre- and post-tax incomes are equivalised using OECD and OECD-modified scales, that is, in the two living-standard scenarios in which this copula is the one that best captures the dependence between the two variables, at first glance, a fact stands out: the highest HI takes place in 2007, precisely the first year of application of the reform that introduced PIT's dual structure in Spain. However, if we look at the evolution of the HI both before and after the reform took place, we observe that there are differences in the profiles, depending on the scale of equivalence applied. For the OECD scale, HI increases every year since 2004 until it reaches its maximum in 2007, decreasing in 2008 and 2009 to values similar to those from 2004, even slightly lower in 2009, although in $2010 \mathrm{HI}$ returns to values close to those from 2006, just before the reform. In contrast, when the modified OECD scale is applied, we observe that after the sustained increase up to 2007, HI falls significantly, being in all years with values clearly below the initial level of 2004, even after the rebound detected for 2010.

In order to properly understand this change in the HI profile, it is necessary to look at the values of the measures obtained using the square root scale, even knowing that with this scale, as we said, Clayton copula is the one that worst captures the dependence for the three years prior to the reform. Applying this scale, the HI exhibits a similar profile to the one 


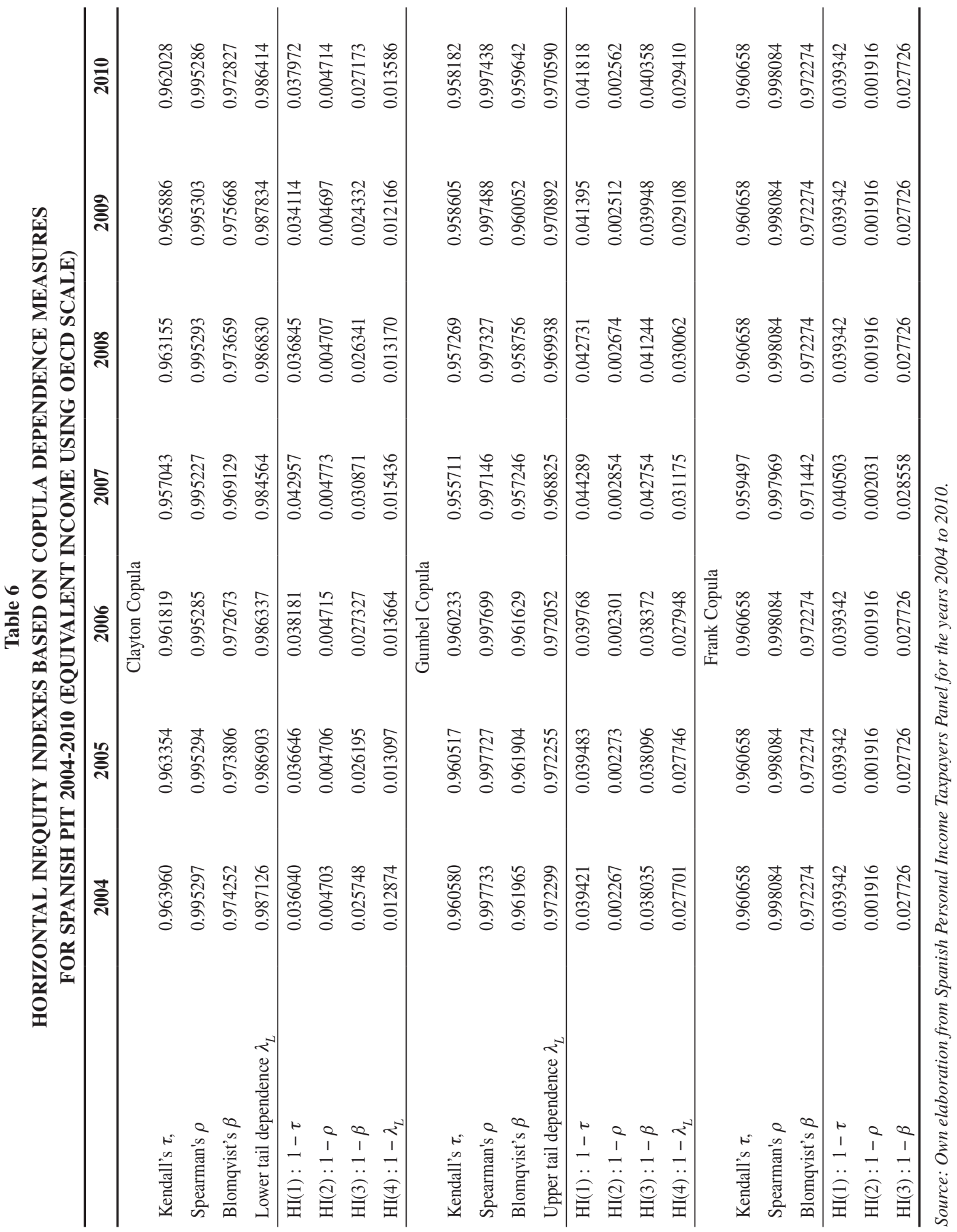




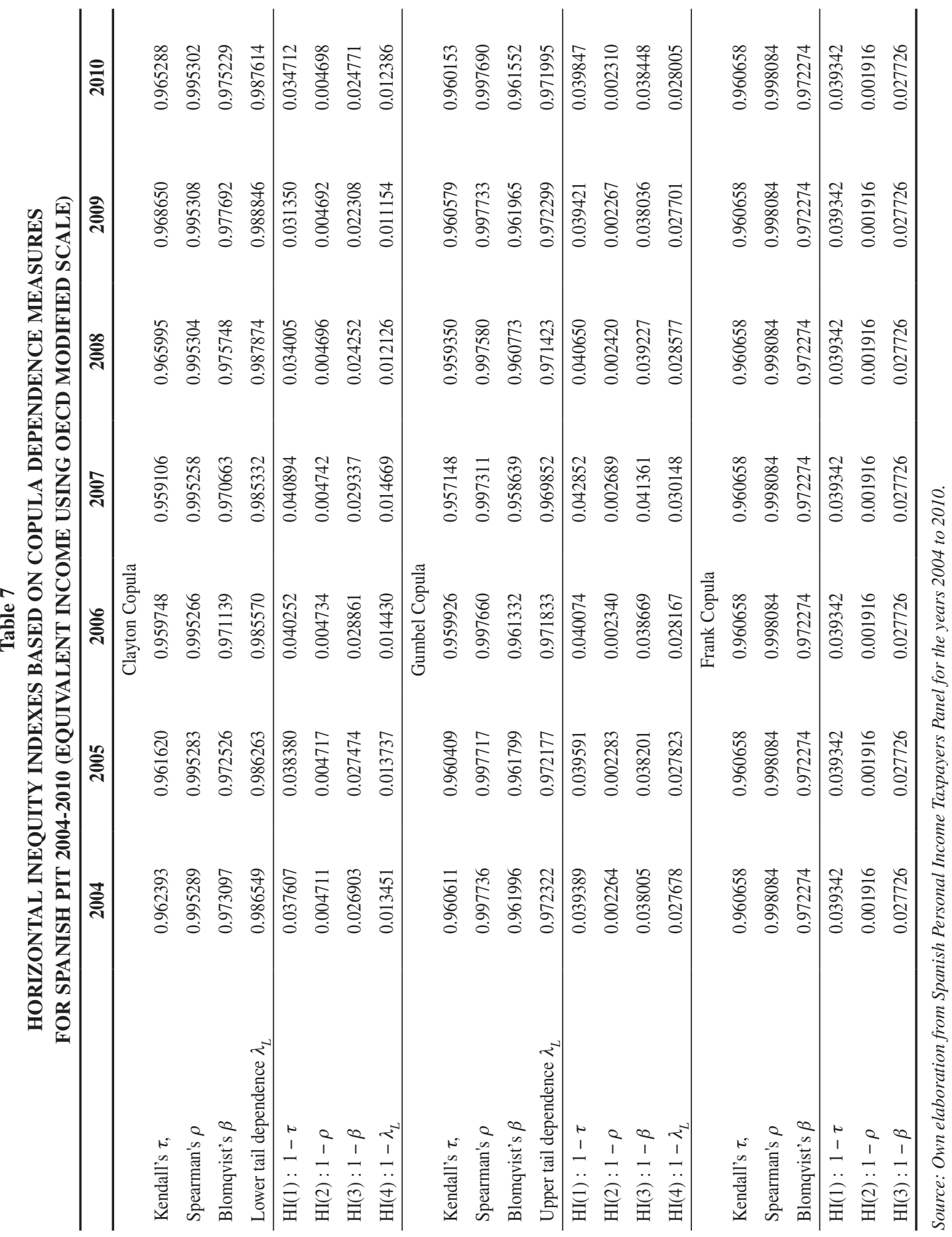




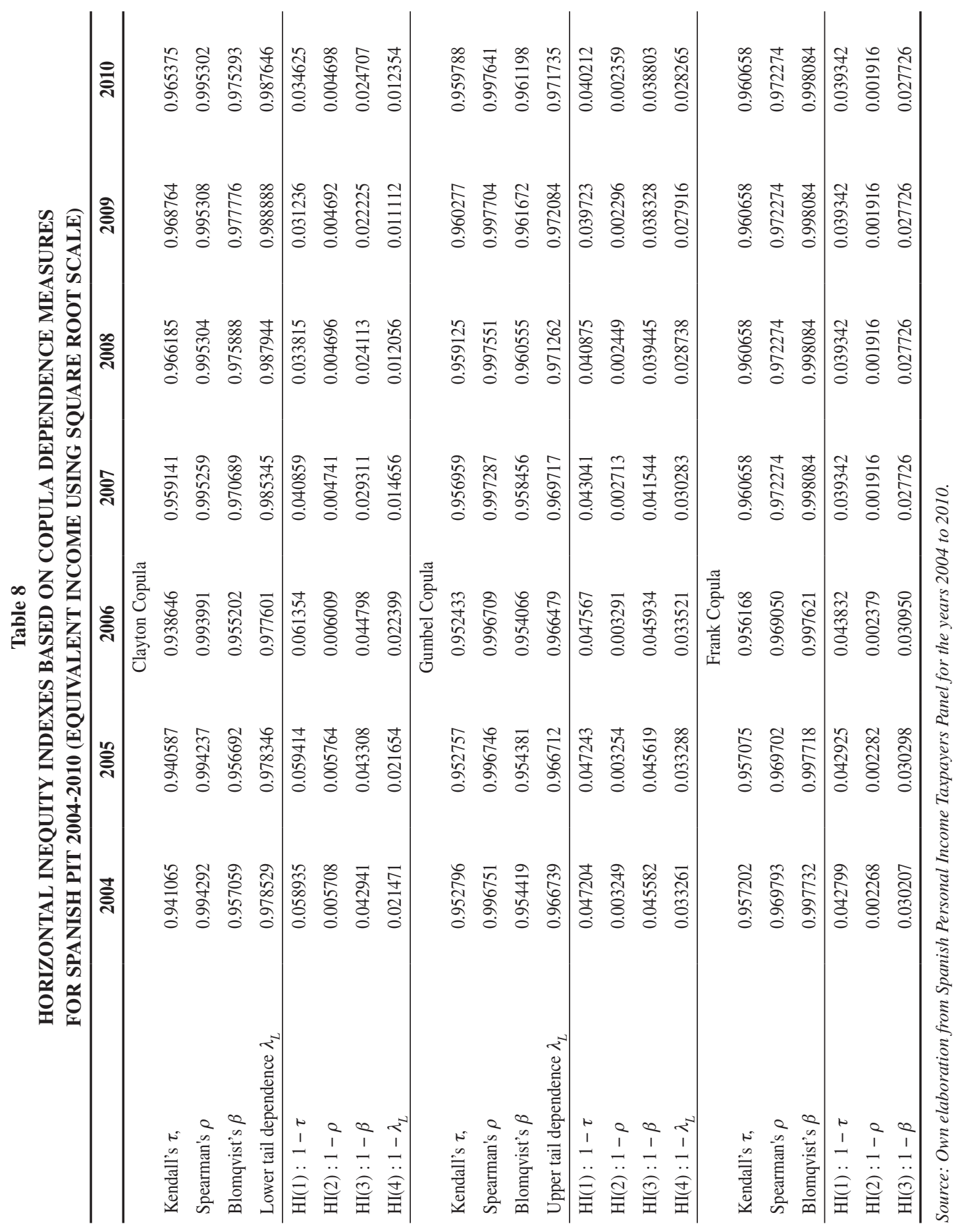



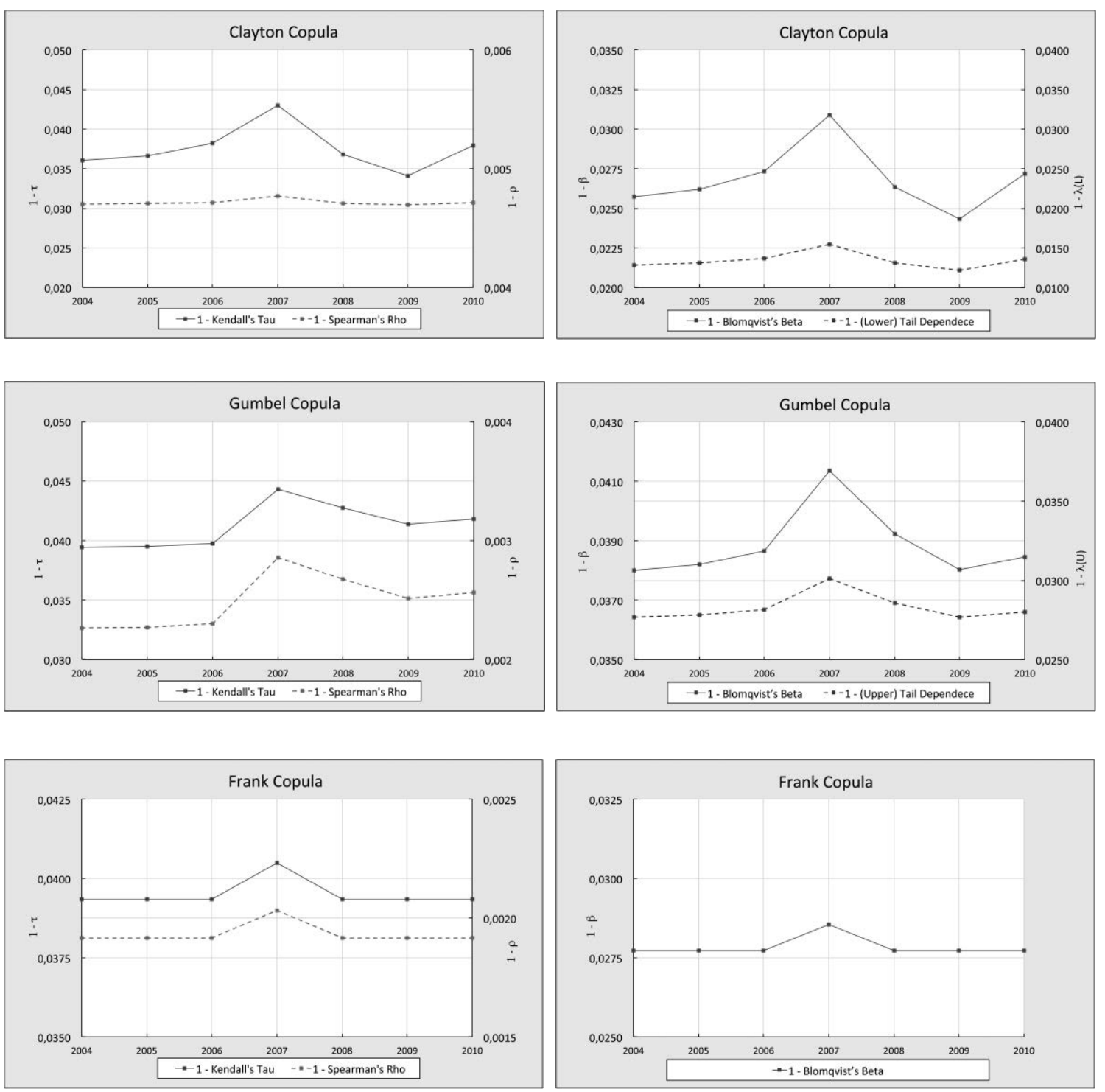

Figure 1: Horizontal Inequity for Spanish PIT 2004 - 2010 based copula estimation (Equivalence scale: OECD)

Source: Own elaboration from Spanish Personal Income Taxpayers Panel for the years 2004 to 2010. 
How Did the 'Dualization' of the Spanish Income Tax Affect Horizontal Equity? Assessing its Impact Using...
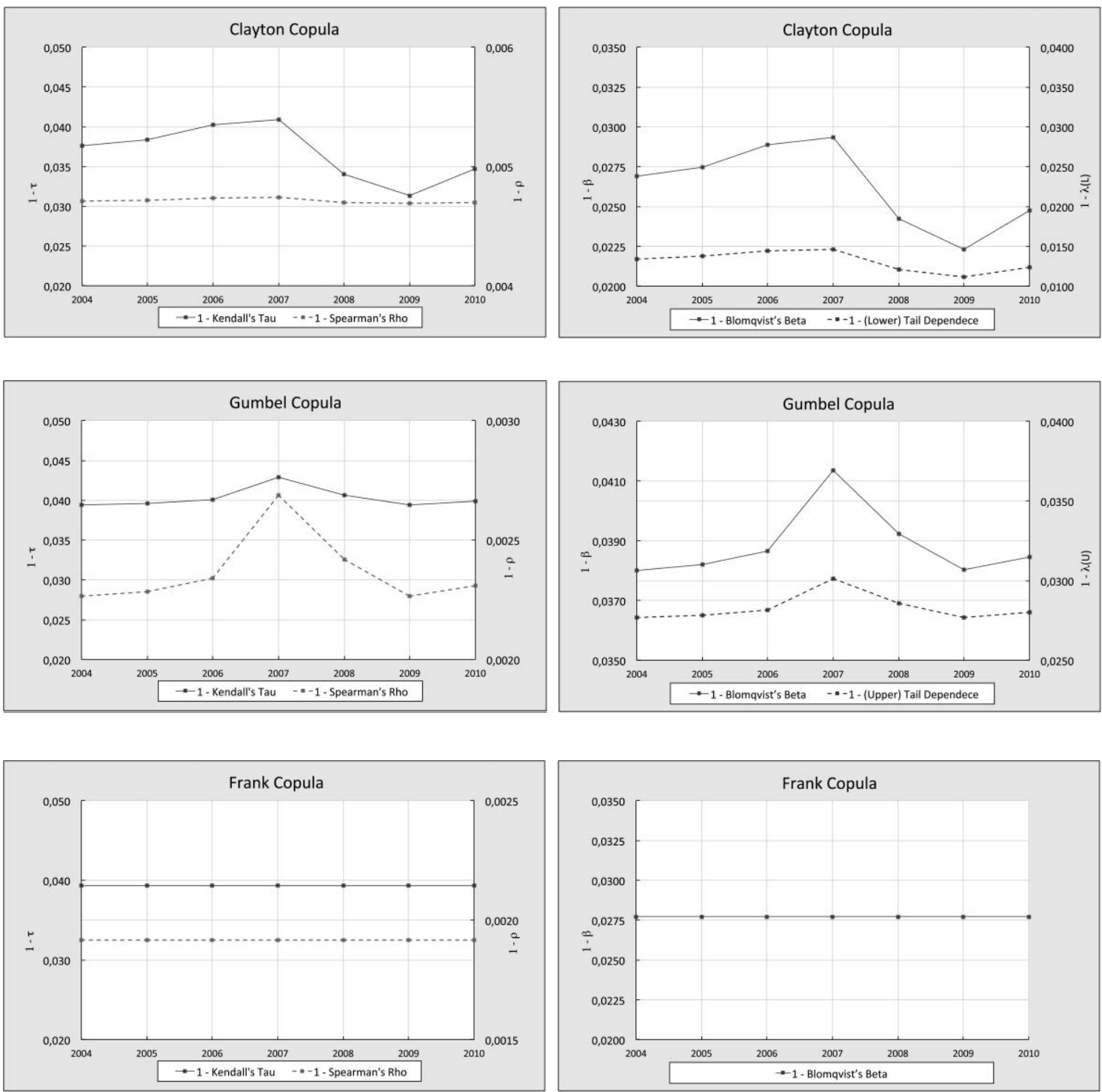

Figure 2: Horizontal Inequity for Spanish PIT 2004 - 2010 based copula estimation (Equivalence scale: OECD modified)

Source: Own elaboration from Spanish Personal Income Taxpayers Panel for the years 2004 to 2010. 

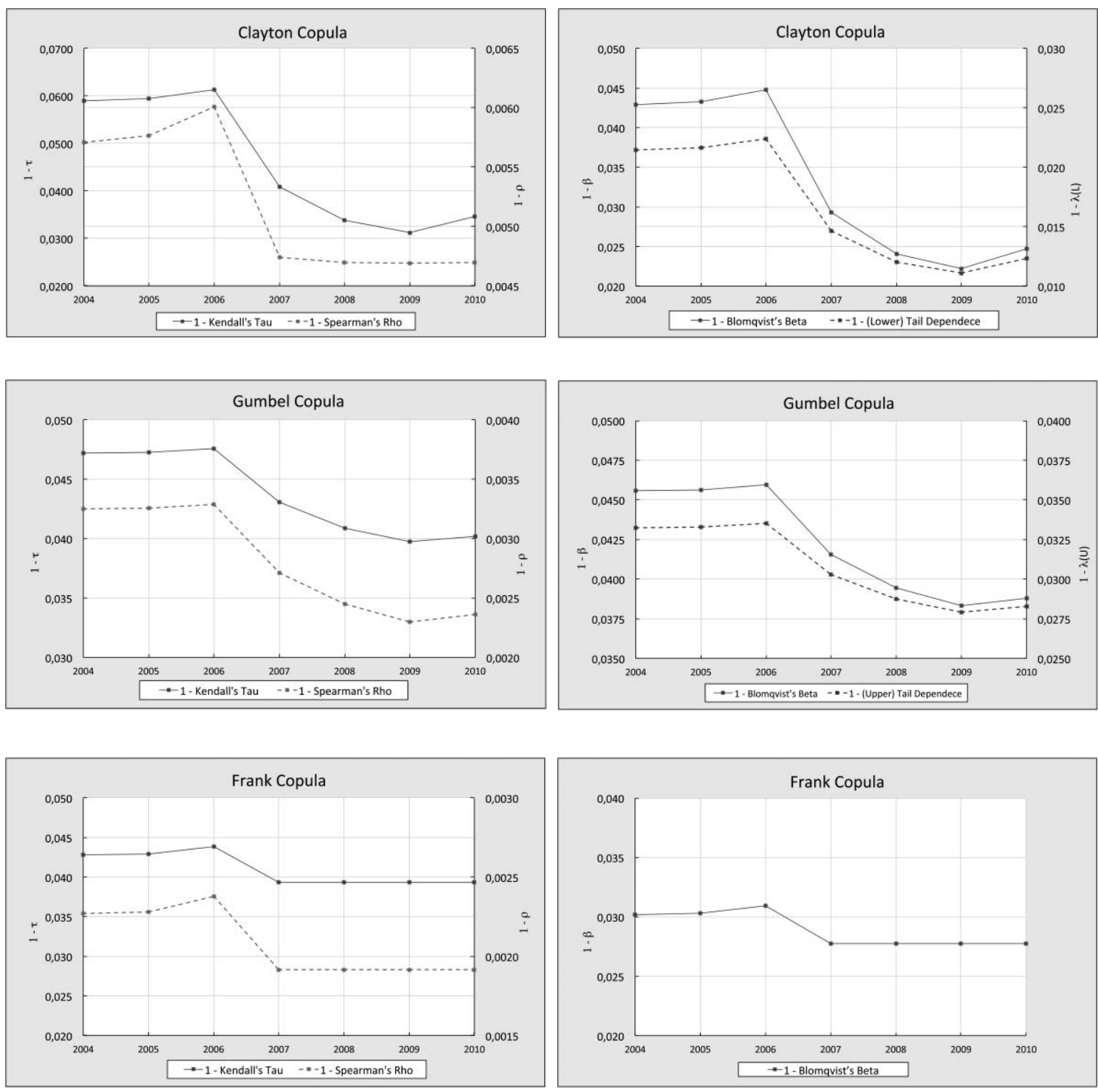

Figure 3: Horizontal Inequity for Spanish PIT 2004 - 2010 based copula estimation (Equivalence scale: Square root)

Source: Own elaboration from Spanish Personal Income Taxpayers Panel for the years 2004 to 2010.

obtained with the modified OECD scale, but reaching its maximum value in 2006, the year preceding the reform. As of 2006, we see how after the application of the dual tax the HI was 
reduced with respect to the value of 2004, around one third in 2007 and in half in 2008, rising, albeit very slightly, in 2010 , as with the rest of the scales.

This result is largely due to the greater economies of scale recognised when using this equivalence scale. As stated in the Introduction, the tax reform in force since 2007, not only introduced a dual tax structure, but it also transformed personal and family allowances into tax credits. Since then, tax savings for these concepts began to be generated at the minimum marginal tax rate of the progressive schedule, instead of doing it at the highest marginal tax rate applicable to each taxpayer, as it happened with the PIT applied in Spain from 1999 to 2006. This change led to an equalization of tax savings related to personal and family circumstances, to the extent that they now depend on the size of the family tax unit (and of course the ages and possible disabilities of its members) instead of on their level of income. In short, through this measure, the 2007 tax reform contributed to mitigate unequal treatment among taxpayers, what obviously should be reflected in the measurement of the IH.

The analysis for the results obtained with the Gumbel copula, for the three scales, shows that the HI profiles are practically the same as those we have just presented for the Clayton copula. Nevertheless, there is an outstanding difference: the decline in HI, from the maximum value reached in 2007 (2006 applying the square root scale), is significantly lower. Finally, the results for the Frank copula evince, as expected, the problems of association of pre- and post-tax income distributions derived from the dependence structure imposed by this copula, which limit its use for the HI measurement.

According to these results, what can we say about the impact of the 2007 Spanish PIT reform on HE? From what we have examined so far, the choice of a certain scale of equivalence to recognise living standards is quite decisive in the HI evaluation of the reform.

In fact, this can be observed in the panels of Figure 4, in which we now compare year after year the values of HI obtained by applying each equivalence scale (measured by $1-\tau$ and $1-\rho$ indices). This transversal analysis allows us to observe how, for the same tax design, each scale results in a different level of HI, showing significant differences sometimes. When we apply a longitudinal interpretation of these panels, the IH ranking by equivalence scale is not the same for every year, nor is the extent of the differences. Specifically, the graphs in Figure 4 show that, during the three years prior to the reform, the HI measurement using the square root equivalence scale is always the one that provides the greatest value. In contrast, for those same years, the lowest levels of HI are obtained when using the OECD scale, followed closely by those that result from applying the modified OECD scale. However, as of 2007, with the entry into force of the tax reform assessed, the highest levels of HI are reached with the OECD scale, while the lowest values are obtained by applying the modified OECD scale, although these are very similar to those provided by the square root scale method.

Although these patterns coincide for the three copulas used, it is necessary to clarify that the square root scale is the only one that generates notable differences with respect to the other two scales, and only during the three years prior to the reform. In contrast, since 2007, 

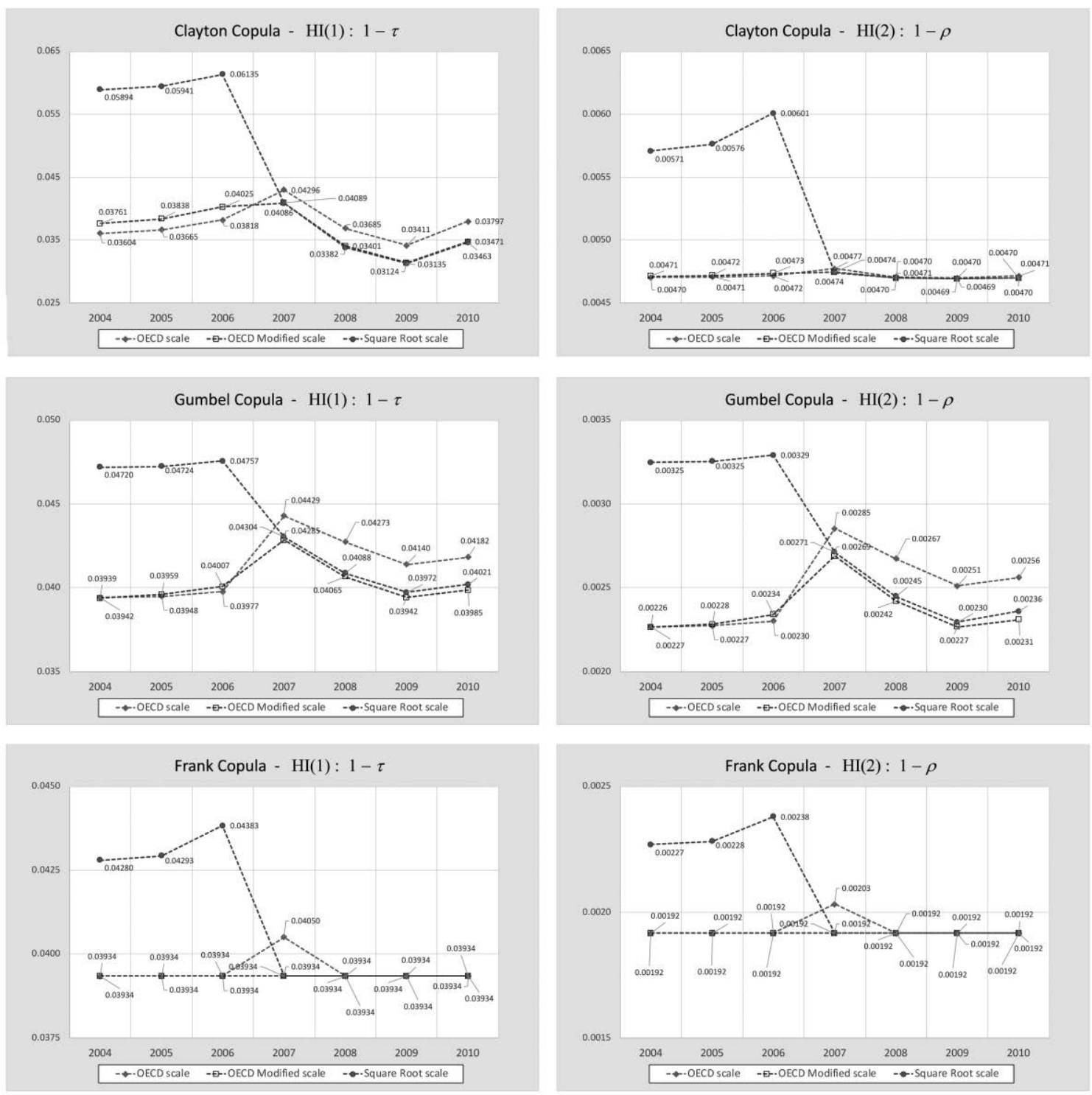

Figure 4: Horizontal Inequity for Spanish PIT 2004 - $2010(1-\tau$ and $1-\rho)$ : Ranking by Equivalence Scales

Source: Own elaboration from Spanish Personal Income Taxpayers Panel for the years 2004 to 2010.

the differences in the HI values according to the scale applied are much smaller, being higher with the Gumbel copula than with the Clayton copula. In the case of Frank copula, 
the differences between equivalence scales are practically negligible, except for 2007 , for which HI calculated using OECD scale is higher.

These empirical results are explained by the economies of scale underlying each of the considered equivalence scales. They interact with the modulation of tax liabilities by personal and family circumstances, let's not forget, linked to the size of the tax family unit. Thus, as we apply a scale that incorporates greater economies of scale (OECD, modified OECD and square root, in this order), and the treatment of personal and family circumstances given by the tax becomes increasingly dependent on the size of the tax family unit.

On the other hand, as already stated, the introduction of the dual tax structure presumably implied a potential increase in unequal treatment for taxpayers with the same ability to pay, depending on the composition of their taxable income by income sources. As shown in Díaz-Caro et al. (2013), a significant drop in the proportion of income taxed at the progressive schedule was experienced in 2007 as a consequence of the Spanish PIT "dualization" (approximately 16\% with respect to 2006), incomes that thereafter became proportionally taxed into the savings base. It should be noted that the greater concentration of these savings incomes in the upper part of the total gross income distribution implied a reduction in the average effective tax rate paid by many tax family units located in that part of the distribution, as can be seen in Figure 5.

The division of the gross taxable income into two bases, one taxed with a progressive schedule and the other taxed at a flat tax rate, undoubtedly forced an increase in $\mathrm{HI}$ in 2007, consistent with what is shown in Figures 1 and 2. Nevertheless, it cannot be overlooked that the continued increase of the capital gains included in the special base in the years before the reform, especially the strong realization of these gains detected for the year 2006 (Onrubia y Picos, 2013; López-Laborda et al., 2018), could help to understand the upward trend of the $\mathrm{HI}$ in the years prior to the reform.

In this same vein, the recent results obtained by López-Laborda et al. (2018), also using the Spanish Personal Income Tax Return Panel from the IEF, evidence the existence of anticipated changes in the taxpayers' behaviour in response to the announcement of the reform that introduced the dual tax. In particular, these authors have tested whether the "dualization" of the Spanish income tax in 2007, which tax savings income at lower rates than general income, encourages an income shifting strategy, contrasting that: "a) taxpayers shift part of their revenues from the general base to that of savings, especially capital gains; b) they shift income from capital income to capital gains; and c) they shift income over time". In addition, these authors have found that these tax planning strategies were carried out almost exclusively by the highestincome taxpayers and the self-employed and non-corporate business owners.

In short, these "anticipation" and "learning/adaptation" effects caused by the 2007 tax reform are again consistent with the evolution of $\mathrm{HI}$ found in our results. With this in mind, the anticipation tax strategies contribute to explain, although not exclusively as we have seen, the increasing trend of the IH until 2007, while the gradual adaptation of the taxpayers to the 
new dual tax design, including the exhaustion of the initial strategies, would help explain the HI decline in 2008 and 2009. Regarding the HI increase observed in 2010, it is worth remembering that in the midst of the economic crisis, several changes in the tax were urgently adopted, among them the replacement of the flat rate applied to the savings base by a specific progressive schedule with two marginal rates of $19 \%$ and $21 \%$.

We must be cautious when assessing how all the changes generated by the 2007 PIT reform have affected the HE of the tax. We can simply say that the behaviour changes that we just mentioned are consistent with the exhibited HI evolution. As we said above, the reform, at the same time that introduced the dual scheme of income taxation causing the effects outlined, also incorporated a sizeable measure favouring $\mathrm{HE}$, as was the transformation of personal and family deductions into tax credits. And all this without forgetting the important influence of the equivalence scale choice. An example of this is when square root scale is applied: the conversion of personal and family allowances into tax credits introduces an HI improvement, which compensates for the worsening of the HI caused by the dualization enough.

All in all, in view of the findings presented, we can say that these reveal two main effects of 2007 tax reform on the HI working in opposite directions. While, on the one hand, the partition of the taxable income into two bases (one of them taxed progressively and another proportionally) increases the HI, on the other hand, the transformation of personal and family allowances into tax credits reduces it. Hence, the net impact of the 2007 PIT reform on HE depends on which of the two effects -pro HE and against HE- predominates, without forgetting the influence of the chosen equivalence scale.

To conclude this analysis, we compare the findings obtained using copula functions with the results provided by Gallego et al. (2012), who used traditional methodologies to measure HI for Spanish PIT during the period 2004 to 2007. We can only compare them with our results for the OECD equivalence scale inasmuch as these traditional HI indices were computed by applying this scale. Specifically, we have values for the period 2004 to 2007 of the indices of Atkinson-Plotnick, Camarero-Herrero-Zubiri (with inequality aversion parameters $c=0, c=1$ and $c=2$ ), and Lambert and Ramos.

Table 9

TRADITIONAL HORIZONTAL INEQUITY INDEXES FOR SPANISH PIT 2004-2007 (EQUIVALENT INCOME USING OECD SCALE)

\begin{tabular}{lllll}
\hline \multicolumn{1}{c}{ Indices } & $\mathbf{2 0 0 4}$ & $\mathbf{2 0 0 5}$ & $\mathbf{2 0 0 6}$ & $\mathbf{2 0 0 7}$ \\
\hline Atkinson - Plotnick & 0.828 & 0.824 & 0.773 & 0.793 \\
Camarero - Herrero - Zubiri & & & & \\
Inequality aversion parameter $\mathrm{c}=0$ & 1.960 & 2.463 & 2.976 & 3.421 \\
Inequality aversion parameter $\mathrm{c}=1$ & 0.900 & 0.987 & 1.095 & 1.003 \\
Inequality aversion parameter c $=2$ & 0.874 & 0.949 & 1.046 & 0.944 \\
\hline Lambert - Ramos & 1.872 & 2.218 & 3.024 & 3.293 \\
\hline
\end{tabular}

Note: All the values are expressed multiplied by 1,000.

Source: Gallego et al. (2012). 
In the same direction as our results for the OECD scale, as it can be seen in Table 9, all these indices reflect a continued increase of the HI until 2007, with the exception of the Camarero-Herrero-Zubiri index, for which inequality aversion values of 1 and 2 shows a decrease in 2007.

\subsection{Horizontal inequity and dispersion of average effective rates}

In order to extend the HI results concerning the dualization of Spanish PIT, we conducted a complementary analysis of the changes caused by the 2007 tax reform in terms of the dispersion of average effective tax rates (defined as tax liability/gross income) across tax family units with similar gross income levels. In doing so, we start from the premise that the $\mathrm{HI}$ of a particular PIT design is associated with the dispersion of the average effective rates (i.e. the coefficient of variation) existing across tax family units with similar gross income. This is so since in the absence of differential tax treatment, they should pay similar tax liabilities. Note, however, that this proposed measure is only approximate, because, given the formal progressivity of PIT, it is inevitable, for the general tax schedule at least, that the average tax rate will increase within the same income bracket with similar non-income attributes. But to the extent that the intervals set to consider "similar gross incomes" are rather small, pure income variations can be considered to have an insignificant effect.

For the purposes of this analysis, we first established gross income intervals in order to identify tax family units with similar abilities to pay. To do this, we used the optimal divisions provided by the Kernel-Epanechnikov method for estimating the gross income density function $^{28}$. For each of these similar gross income intervals, we calculated the mean of the average effective tax rates borne by the different tax units belonging to this interval for both 2006 and 2007, as well as the maximum and minimum values of the interval.

As Figure 5 shows, although the reform cuts the top marginal tax rate of the progressive schedule (from $45 \%$ to $43 \%$ ), from a gross income level of around 50,000 euro, tax family units of each interval paid in 2007, on average, a higher effective average rate than in 2006. Below that threshold, the mean of the effective average rates for each interval was lower than the one corresponding to the 2006 tax period. As we have previously explained, the combination of measures introduced by the reform is behind this result, highlighting precisely the effect of the change in tax treatment of personal and family circumstances on those taxpayers affected by the highest marginal rates, who were clearly harmed by the transformation of tax allowances into tax credits. When we consider the equivalent income, the threshold from which the average effective tax rates of 2007 are higher, on average per interval, than with the 2006 tax, falls below 50,000 euro, although this is growing as that we use a scale with greater economies of scale (around 20,000, 25,000 and 30,000 euro respectively).

As we stated, assessing the impact of dualization on the HI based on the distribution of effective average tax rates requires focusing on the changes introduced by the reform in its dispersion for similar ability to pay tranches. Figure 6 compares the values of the coefficient 

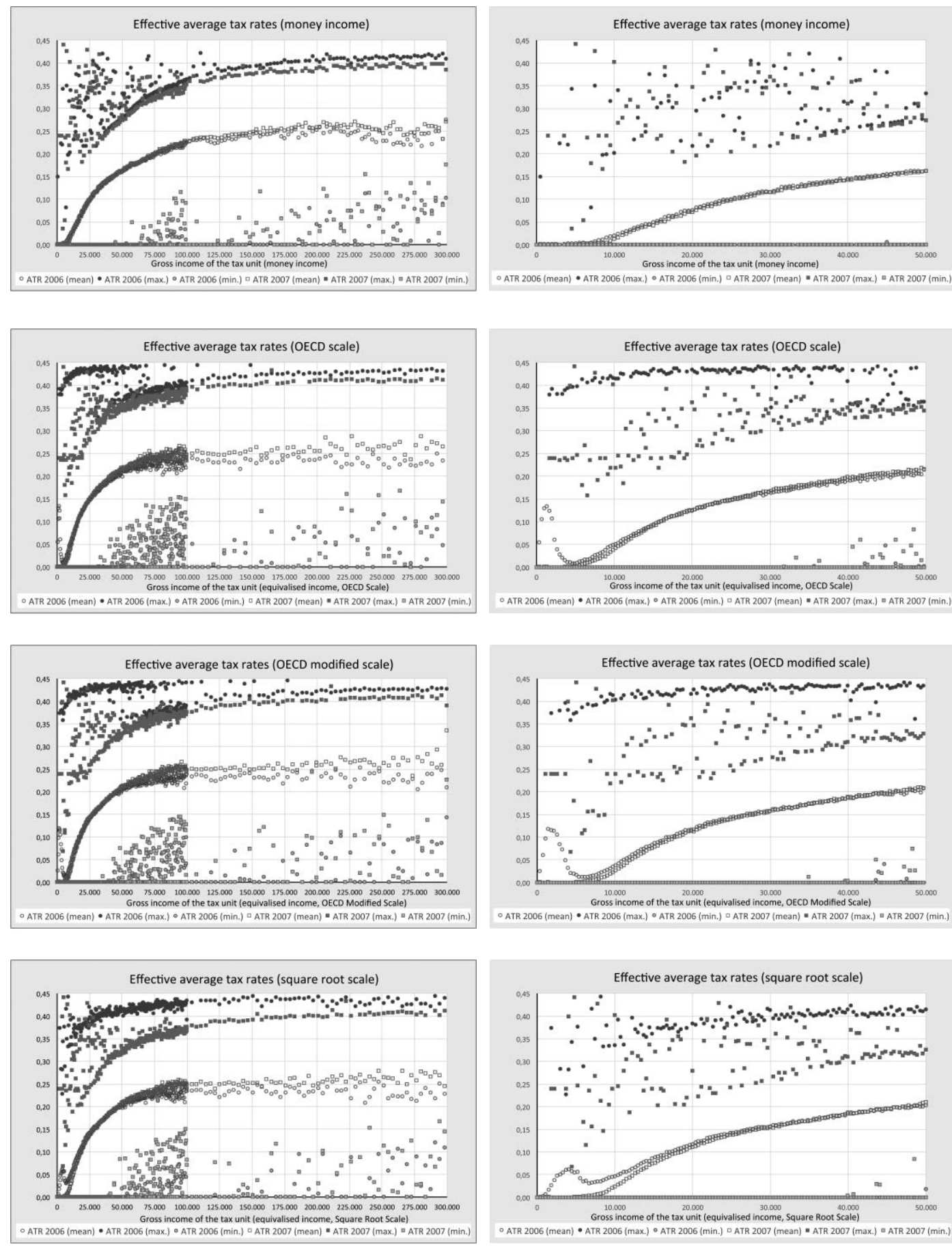

Figure 5: Effective average tax rates for 2006 and 2007 Spanish PIT (by partitions of similar ability to pay)

Source: Own elaboration from Spanish Personal Income Taxpayers Panel for the years 2004 to 2010. 

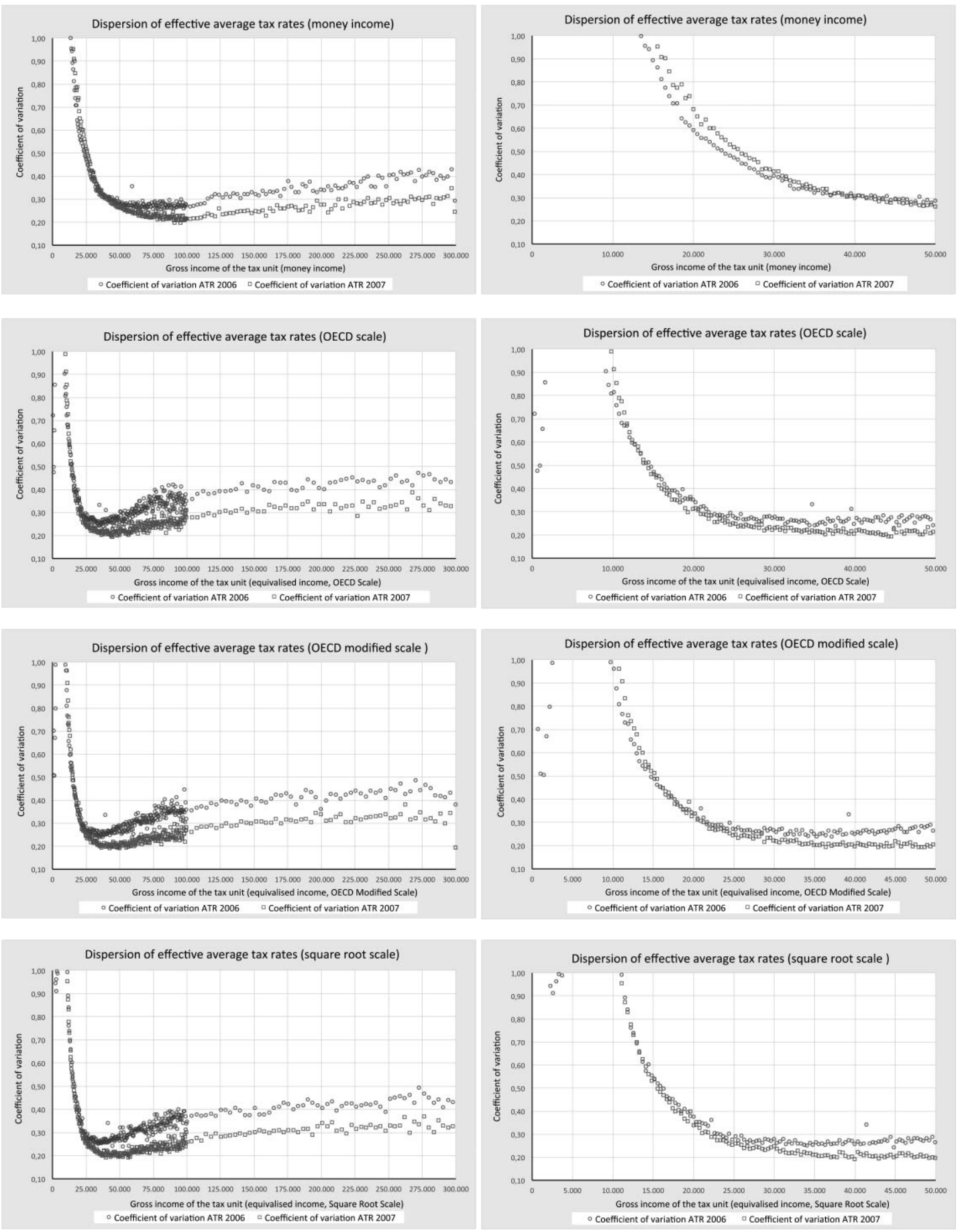

Figure 6: Effective average tax rates: Coefficients of variation for 2006 and 2007 Spanish PIT (by partitions of similar ability to pay up to 100,000 euro)

Source: Own elaboration from Spanish Personal Income Taxpayers Panel for the years 2004 to 2010. 
of variation for each interval of similar gross income for pre- and post-tax reform years. To give a better picture of these results, right-panels illustrate the same comparison in this case for the income intervals ranging from 0 to 50,000 euro.

According to these findings, we find that, in 2007, with monetary income, the DIT raised the coefficient of variation for similar tax units, with respect to the 2006 tax, up to a gross income level around 40,000 euro. From this threshold, we see that the tax applied in 2006 generated a greater dispersion in the effective average rates, slightly increasing with the income. As it can be seen, this result is repeated when we consider equivalent income. But it should be noted that the greater dispersion of the effective average rates corresponding to the 2006 tax now occurs from a threshold around 15,000 euro, that is, more or less the same income amount for the three scales applied. Even so, it is noteworthy that up to that threshold, differences between the coefficients of variation of both taxes are somewhat higher when using OECD and OECD modified scales than when the square root scale is applied.

We can conclude that these patterns of dispersion of the effective average tax rates for both PIT designs are fully consistent with the findings with respect to the HI calculated using copula functions. To understand this, we must bear in mind that the density of tax units with incomes below this threshold of about 15,000 euro, mostly affected by the greater dispersion of the average rates of DIT, is determinant to order both tax designs in terms of HI. In this sense, the highest relative intensity of this dispersion when we apply the OECD and OECD modified scales coincides with the higher IH found for the 2007 DIT using the indices associated with copulas.

\section{Concluding remarks}

Public finance literature has traditionally considered the HE principle of taxation as an essential concept in the design of PITs. However, it is generally agreed that this command of equity is not easy to implement in tax reforms. As differentiated tax treatments are embedded in the structure of PIT, different requirements have to be taken into account to determine who should be considered as equals for the purpose of applying this principle. But in spite of everything, we agree that $\mathrm{HE}$ is one of the key aspects to be taken into account when evaluating a tax system, not only because of its indisputable effects on distributive justice, but also due to its implications for voluntary tax compliance and tax morale as a whole.

The main purpose of this article was to assess how the introduction in 2007 of a dual taxation model (or rather "semi-dual", as argued in the Introduction) has affected the HI of the Spanish PIT, cornerstone of our tax system. We believe that it is worth analysing how dual income tax may violate HE command since it taxes differently both components of the personal ability to pay, which in turn incentives income-shifting behaviours between the two tax bases. This problem foreseeably leads to a greater HI that should be properly measured. 
To carry out this evaluation, we have opted for the methodology based on the parametric estimation of copula functions proposed by $\mathrm{B} \emptyset$ et al. (2012), which is fully consistent with the theoretical foundations on HI measurement stated in Dardanoni and Lambert (2001). In this sense, we believe that this research contributes to expand the scarce literature that use this attractive methodology to evaluate the HE of the tax systems.

Our results suggest that the Spanish PIT reform that came into force in 2007 caused two effects on HI working in opposite directions, so we must be cautious when assessing separately their contribution to the overall impact on HE. First, as expected, the partition of the taxable income into two bases, one of them taxed progressively and another proportionally, increased the HI. Second, apart from dualization, the reform transformed personal and family allowances into tax credits, a change considered favourable for HE. Moreover, existing empirical evidence reveals that in the year prior to the dualization, tax planning behaviours that anticipated the effects of the reform occurred, being compatible with the HI evolution found. Similarly, results obtained for the years after the reform came into effect are also consistent with taxpayers' adaptation behaviour to the new dual tax structure, which would explain the HI decline in 2008 and 2009.

But we cannot ignore the important influence of the equivalence scale choice. In this regard, obtained results show that as the scale recognises greater economies of scale, the "dualization effect", contrary to the HE, loses relevance in favour of the effect generated by the new treatment of personal and family circumstances through tax credits, favourable to the HE. These findings are corroborated by the analysis of the effective average tax rates dispersion along the distribution of gross income. All in all, we can conclude that the net impact of the Spanish PIT dualization depends on which of the two effects -pro HE and against HE- dominates, not to forget the influence on the result of the equivalence scale chosen.

Finally, we think that there is still room for further research. In particular, the HI analysis might be conducted for Spanish Autonomous Communities, paying attention to the differences in gross income composition by sources. We consider that such an extension would be interesting and valuable due to the existence of regional asymmetries on tax schedules for general taxable income and tax credits. From a theoretical viewpoint, we think it might be interesting to analyse the relationship between the dispersion of effective average tax rates and the dependence between pre- and post-tax income distributions captured by copulas.

\section{Notes}

1. See Sørensen (1994, 1998), Nielsen and Sørensen (1997) and Sørensen (2005) for characteristics of dual income tax, its properties and limitations.

2. See Eggert and Genser (2005) and Genser and Reutter (2007) for the evolution of dual income tax in Europe.

3. Kaldor (1955) first proposed the use of personal expenditure as an indicator of ability to pay in direct taxation, which was later considered in several reports on fiscal reform such as Bradford (1977), the Meade Commission (1978) and Lodin (1978). 
4. These tax credits are calculated by applying the general tax schedule to the allowances, although increased compared to 2006 amounts.

5. Kaplow (1989) and Kaplow and Shavell (2002) expressed reservations about the relevance of HE with regard to tax design, noting the lack of practical implementation of this equity principle.

6. An interesting discussion about the relationship between HE, tax compliance and tax morale is offered in Lindsay (2016).

7. Some of these tax planning strategies (if not, tax avoidance) have been empirically analysed, among others, by Alstadsaeter and Jacob (2016) for Sweden, Pirttilä and Selin (2011) and Harju and Matikka (2016) for Finland, and López-Laborda et al. (2018) for Spain.

8. On the scope of the term "semi-dual" and its differences with the pure dual model can be seen OECD (2006, p. 81).

9. In 2010, a tax schedule with two marginal tax rates substituted the flat rate for the savings base (19\% for up to 6,000 euro of taxable income and $21 \%$ for amount above that figure). This savings tax schedule was later modified in 2015 to include a third bracket (19\% for up to 6,000 euro of taxable income, $21 \%$ for up to 50,000 euro, and $23 \%$ for amounts above that figure in 2016).

10. In addition, from 1997 to 2006, a transitional tax regime was applied for assets acquired before 31 December 1994. Taxable capital gains resulting from those assets were proportionately reduced depending on how many years had been held in the portfolio and which type of asset they were. The regime was maintained after the 2007 PIT reform for those taxpayers who had previously benefited from it. However, it is only applied in proportion to the time elapsed between the acquisition of the asset and the date on which the reform entered the Parliament (19 January 2006), whilst the rest of the capital gain is taxed without any correction.

11. When personal and family minimums are greater than the general base, the flat rate for the savings base (18\%) is applied to the remainder in order to calculate the taxpayer's total tax credit.

12. It should be clarified that this change in the tax structure was not equivalent in terms of equal yield, either individually or for all taxpayers as a whole.

13. Johnson and Mayer (1962) and Brennan (1971) are often considered as the originators of this classical strand.

14. Perrote et al. (2003) use these non-parametric techniques to analyze HI in Spanish personal income tax.

15. In the assessment of living standards through income, it is appropriate to use an equivalence scale that allows taking into account the differences in needs related to the size of the tax units. In this sense, $x$ and $y$ can be expressed in terms of total money income or, alternatively, in terms of equivalent income, by applying an equivalence scale.

16. In our case, monotonic transformation of income, $v(x)$, is the result of applying the assessed tax structure, in equivalent terms, $u(y)$.

17. For an in-depth review of the copula concept and its properties, see Joe (1997) and Nelsen (2006).

18. This theorem was originally published in French. A similar article written in English was published in 1973 (Sklar, 1973).

19. For this demonstration it can see Nelsen (2006).

20. In their empirical illustration, DL (2001) estimate discrete copulas for United Kingdom, Israel and Canada using the Iterative Proportional Fitting algorithmic procedure for very small sample sizes $(2,721,5,212$ and 4,000 cases, respectively).

21. Although it does not happen in our case, regarding to potential overidentification problems, the number of parameters must be to taken into account in the goodness-of-fit tests.

22. For more information about this database, see Onrubia et al. (2011), Onrubia and Picos (2012) and Pérez et al. (2018).

23. The common fiscal regime excludes the Autonomous Communities of the Basque Country and Navarre, which have separate personal income tax systems. 
24. Combining marital status and the taxation regime (individual or joint filing), Spanish PIT Law differentiates four categories of tax unit: unmarried individuals (irrespective of whether the individual is single, separate, divorced or widowed); single-parent families (unmarried individuals with children under the age of 18, excluding unmarried couples living together); married couples with one income earner (filing jointly); and married couples with two income earners (with each spouse filing separately).

25. Dependent descendants and ascendants can be identified from the tax returns within the Spanish Institute for Fiscal Studies Personal Income Tax Panel.

26. See OECD (2019).

27. The "savings base" was called "special base" in the PIT system applied between the years 1996 and 2006.

28. We make a distinction between two levels of gross income: from 0 to 100,000 euro and from 100,000 to 300,000 euro. For the first level, the optimal divisions have been set at 500 euro, 327 euro, 360 euro, and 370 euro, respectively for monetary and equivalent income distributions applying the OECD, OECD modified and square root scales. And for the second level, the optimal intervals have been set, respectively, at 2,700, 4,100, 3,700 and 3,600 euro.

\section{References}

Akaike, H. (1974), "A new look at the statistical model identification", IEEE Transactions on Automatic Control, 19 (6): 716-723.

Alstadsaeter, A. and Jacob, M. (2016), "Dividend taxes and income shifting", Scandinavian Journal of Economics, 118(4): 693-717.

Aronson, R., Johnson, P. and Lambert, P. J. (1994), "Redistributive Effect and Unequal Income Tax Treatment in the U.K.", Economic Journal, 104(423): 262-270.

Atkinson, A. (1980), "Horizontal Equity and the Distribution of the Tax Burden", in H. Aaron and M. Boskin (eds.), The Economics of Taxation, Washington DC: The Brooking Institution.

Atkinson, A. B. and Bourguignon, F. (1982), "The comparison of multi-dimensioned distributions of economic status", Review of Economic Studies, 49(2): 183-201.

Atkinson, A. B. and Stiglitz, J. E. (1976), "The Design of Tax Structure: Direct vs. Indirect Taxation", Journal of Public Economics, 6(1-2): 55-75.

Auerbach, A. and Hassett, K. (2002), "A New Measure of Horizontal Equity", American Economic Review, 92(4): 1116-1125.

Berliant, M. and Strauss, P. (1983), "Measuring the Distribution of Personal Income Tax", in R. Zeckhauser and D. Leebaert (eds.), What Role for the Government? Lessons from Policy Research, Durham, NC: Duke University Press.

Blomqvist, N. (1950), "On a measure of dependence between two random variables", Annals of Mathematical Statistics, 21(4): 593-600.

Bø, E. E., Lambert, P. J. and Thoresen, T. O. (2012), "Horizontal Inequity under a Dual Income Tax System: Principles and Measurement”, International Tax and Public Finance, 19(5): 625-640.

Boadway, R. (2004), “The Dual Income Tax System: an Overview”, CESifo DICE Report, 2(3): $3-8$. 
Boadway, R. (2011), "Individual income taxation: income, comsuption, or dual?", in E. Albi and J. Martínez-Vázquez (eds.), The Edgar Guide to Tax Systems, Cheltenham, UK: Edward Elgar, 93-129.

Bradford, D. F. (ed.) (1977), Blueprints for Basic Tax Reform, Washington DC: U.S. Government Printing Office.

Brennan, G. (1971), "Horizontal Equity: an Extension of an Extension", Public Finance/Finances Publiques, 26(3): 437-456.

Caillault, C. and Guegan, D. (2005), "Empirical estimation of tail dependence using copulas: application to Asian markets", Quantitative Finance, 5(5): 489-501.

Camarero, R., Herrero, O. and Zubiri, I. (1993), "La Medición de la Inequidad Horizontal: Teoría y una Aplicación al caso de Vizcaya”, Investigaciones Económicas, 17(2): 333-362.

Clayton, D. G. (1978), "A Model for Association in Bivariate Life Tables and Its Application in Epidemiological Studies of Familial Tendency in Chronic Disease Incidence", Biometrika, 65(1): 141-151.

Cowell, F. (1985), "Measures of Distributional Change: an Axiomatic Approach", Review of Economic Studies, 52(1): 135-151.

Crawford, C. and Freedman, J. (2010), "Small Business Taxation”, in J. Mirrlees, S. Adam, S., T. Besley, R. Blundell, S. Bond, R. Chote, M. Gammie, P. Johnson, G. Myles and J. Poterba (eds.), Dimensions of Tax Design: The Mirrlees Review, London: Institute of Fiscal Studies and Oxford University Press, 1028-1099.

Dardanoni, V. and Lambert, P. J. (2001), "Horizontal Inequity Comparisons", Social Choice and Welfare, 18(4): 799-816.

Diamond, P. A. (2007), "Comment on Golosov et al.", in D. Acemoglu, K. Rogoff and M. Woodford (eds.), NBER Macroeconomics Annual 2006, The MIT Press, 365-379.

Díaz-Caro, C., J. Onrubia and Pérez-Mayo, J. (2013), "Progresividad y Redistribución por Fuentes de Renta en el IRPF dual", Hacienda Pública Española/Review of Public Economics, 206: 57-87.

Duclos, J. Y., Jalbert, V. and Araar, A. (2003), “Classical Horizontal Inequity and Reranking: An Integrated Approach", Research on Economic Inequality, 10: 65-100.

Duclos, J. Y. and Lambert, P. J. (2000), “A Normative and Statistical Approach to Measuring Classical Horizontal Inequity", Canadian Journal of Economics/Revue Canadienne d'Économique, 33(1): 87-113.

Eggert, W. and Genser, B. (2005), "Dual Income Taxation in EU Member Countries", CESifo DICE Report, 3(1): 41-47.

Feldstein, M (1976), “On the Theory of Tax Reform”, Journal of Public Economics, 6(1-2): 77-104.

Frank, M. J. (1979), "On the Simultaneous Associativity of $\mathrm{F}(\mathrm{x}, \mathrm{y})$ and $\mathrm{x}+\mathrm{y}-\mathrm{F}(\mathrm{x}, \mathrm{y})$ ”, Aequationes Mathematicae, 19(1): 194-226.

Gallego, C. P., Onrubia, J. and Picos, F. (2012), "Inequidad Horizontal en el IRPF Español, 20032007”, XIX Encuentro de Economía Pública, 26-27 de enero, Santiago de Compostela.

Genest, C. and Rivest, L. P. (1993), "Statistical inference procedures for bivariate Archimedean copulas", Journal of the American Statistical Association, 88(423): 1034-1043. 
Genser, B. and Reutter, A. (2007), "Moving Towards Dual Income Taxation in Europe", FinanzArchiv: Public Finance Analysis, 63(3): 436-456.

Griffith, R., Hines, J. and Sørensen, P. B. (2010), "International Capital Taxation”, in J. Mirrlees, S. Adam, T. Besley, R. Blundell, S. Bond, R. Chote, M. Gammie, P. Johnson, G. Myles, and J. Poterba (eds.), Dimensions of Tax Design: The Mirrlees Review, London: Institute of Fiscal Studies and Oxford University Press, 914-996.

Gumbel, E. J. (1960), "Bivariate Exponential Distributions", Journal of the American Statistical Association, 55: 698-707.

Harju, J., and Matikka, T. (2016), "The elasticity of taxable income and income-shifting: what is 'real' and what is not?", International Tax and Public Finance, 23(4): 640-669.

Hofert, M., Kojadinovic, I., Mächler, M. and Yan, J. (2018a). “Copula: Multivariate Dependence with Copulas. R package version 0.999-19" https://CRAN.R-project.org/package=copula

Hofert, M., Kojadinovic, I., Mächler, M., Yan J. (2018b), Elements of Copula Modeling with R. Use R! Cham, Switzerland: Springer.

Jenkins, S. (1988), "Empirical Measurement of Horizontal Inequality", Journal of Public Economics, 37(3): 305-329.

Jenkins, S. P. and Lambert, P. J. (1999), "Horizontal Inequity Measurement: a Basic Reassessment”, in J. Silber (ed.), Handbook on Income Inequality Measurement, Norwell, MA: Kluwer Academic Publishing, 535-553.

Joe, H. (1997), Multivariate models and dependence concepts, New York: Chapman \& Hall.

Johnson, S. and Mayer, T. (1962), “An Extension of Sidgewick's Equity Principle”, Quarterly Journal of Economics, 76(3): 454-463.

Kaldor, N. (1955), An Expenditure Tax, London: Allen and Unwin.

Kaplow, L. (1989), "Horizontal Equity: Measures in Search of a Principle", National Tax Journal, 42(2): 139-154.

Kaplow, L and Shavell, S. (2002), Fairness versus Welfare, Cambridge, MA: Harvard University Press.

Kendall, M. (1938), “A New Measure of Rank Correlation”, Biometrika, 30(1-2): 81-93.

King, M. (1983), “An Index of Inequality with Applications to Horizontal Equity and Social Mobility”, Econometrica, 51(1): 99-115.

Lambert, P. J. (2001), Distribution and Redistribution of Income, 3rd edition, Manchester, UK: Manchester University Press.

Lambert, P. J. and Ramos, X. (1997a), "Horizontal Inequity and Reranking: A Review and Simulation Study”, Research on Economic Inequality, 7: 1-18.

Lambert, P. J. and Ramos, X. (1997b), "Horizontal Inequity and Vertical Redistribution”, International Tax and Public Finance, 4(1): 25-37.

Lambert, P. J. and Thoresen, T. O. (2012), “The Inequality Effects of a Dual Income Tax System”, B. E. Journal of Economic Analysis \& Policy - Advances, 12(1): 1-15. 
Lindsay, I. K. (2016), “Tax Fairness by Convention: A Defense of Horizontal Equity”, Florida Tax Review, 19 (2): 79-119.

Lodin, S. O. (1978), Progressive Expenditure Tax, an Alternative? A Report of the 1972 Government Commission on Taxation, Stockholm: LiberFörlag,

López-Laborda, J. (2006), “Capital Gains Taxation and Progressivity”, Papeles de Trabajo, 1/06, Instituto de Estudios Fiscales. http://www.ief.es/docs/destacados/publicaciones/papeles_trabajo/2006_01. pdf

López-Laborda, J., Vallés, J. and Zárate, A. (2018), "Income Shifting in the Spanish Dual Income Tax", Fiscal Studies, 39(1): 95-120.

Meade Commission (1978), Structure and Reform of Direct Taxation, London: Allen and Unwin.

Moreno, M. C. (1996), "Teoría y Medición de la Equidad Horizontal en el Sistema Impositivo", Hacienda Pública Española, 136: 71-92.

Nelsen, R. B. (2003), "Properties and applications of copulas: A brief survey", in J. Dhaene, N. Kolev, and P. A. Morettin (eds.), Proceedings of the First Brazilian Conference on Statistical Modelling in Insurance and Finance, Sao Paulo (Brazil): University of Sao Paulo, 10-28.

Nelsen, R. B. (2006), An introduction to copula, 2nd ed., New York: Springer.

Nielsen, S. B. and Sørensen, P. B. (1997), "On the Optimality of the Nordic System of Dual Income Taxation", Journal of Public Economics, 63(3): 311-329.

OECD (2006), "Fundamental reform of personal income tax", OECD Tax Policy Studies, 13, Paris: OECD Publishing. https://www.oecd-ilibrary.org/docserver/9789264025783-en.pdf?expires=15530 91208\&id=id\&accname $=$ ocid56028003 $\&$ checksum $=404509$ AA4A25AFE23BD22A27A3ABC126

OECD (2019), "What are equivalence scales?", Adjusting household incomes: equivalence scales OECD.org Document. http://www.oecd.org/els/soc/OECD-Note-EquivalenceScales.pdf

Onrubia, J. and Picos, F. (2012), “Diseño, contenido y aplicaciones del nuevo Panel de Declarantes de IRPF 1999-2007”, Revista de Economía Aplicada, 60: 53-87.

Onrubia, J. and Picos, F. (2013), "Desigualdad de la renta y redistribución a través del IRPF, 19992007”, Revista de Economía Aplicada, 63: 75-115.

Onrubia, J., F. Picos and C. Pérez (2011), Panel de Declarantes de IRPF 1997-2007: Diseño, metodología y guía de utilización, Madrid: Instituto de Estudios Fiscales.

Onrubia, J., Picos, F. and Rodado, M. C. (2014), "Rethinking the Pfähler-Lambert Decomposition to Analyse Real-World Personal Income Taxes", International Tax and Public Finance, 21(4): 796-812.

Pazos M., Rabadán, I. and Salas, R. (1995), "La Desigualdad Horizontal en el Impuesto sobre la Renta de las Personas Físicas”, Revista de Economía Aplicada, 9: 5-20.

Pérez, C., Villanueva, J. and Molinero, I. (2018), "Panel de declarantes de IRPF 1999-2014: metodología, estructura y variables ( $1^{\mathrm{a}}$ ed.)", Documento de Trabajo, 5/2018, Instituto de Estudios Fiscales. http://www.ief.es/docs/destacados/publicaciones/documentos_trabajo/2018_05.pdf

Perrote, I. (2007), "La Inequidad Horizontal en la Imposición Personal sobre la Renta, 1982-1998", Información Comercial Española, 837: 71-82. 
Perrote, I., Rodríguez, J. G. and Salas, R. (2003), "La Inequidad Horizontal y la Redistribución Vertical en el Impuesto sobre la Renta de las Personas Físicas: un Análisis de Robustez”, Hacienda Pública Española/Revista de Economía Pública, 166: 49-60.

Pirttilä, J. and Selin, H. (2011), "Income shifting within a dual income tax system: evidence from the Finnish tax reform of 1993", Scandinavian Journal of Economics, 113(1): 120-44.

Plotnick, R. (1981), “A Measure of Horizontal Inequity”, Review of Economics and Statistics, 63(2): 283-288.

Schwarz, G. E. (1978), "Estimating the dimension of a model”, Annals of Statistics, 6(2): 461-464.

Schweizer, B. and Wolff, E. F. (1981), "On non-parametric measures of dependence for random variables", Annals of Statistics, 9(4): 879-885.

Shoup, C. S. (1969), Public Finance, New York: Aldine Publishing.

Simons, H. (1950), Federal Tax Reform, Chicago, IL: University of Chicago Press.

Sklar, A. (1959), "Fonctions de répartition à n dimensions et leurs marges", Publications de l'Institut de Statistique de l'Université de Paris, 8: 229-231.

Sklar, A. (1973), "Random Variables, Joint Distributions and Copulas", Kybernetica, 9(6): 449-460.

Sørensen, P. B. (1994), "From the Global Income Tax to the Dual Income Tax: Recent Tax Reforms in the Nordic Countries", International Tax and Public Finance, 1(1): 57-79.

Sørensen, P. B. (1998), "Recent Innovations in Nordic Tax Policy: from the Global Income Tax to the Dual Income Tax”, in P. B. Sørensen (ed.), Tax policy in the Nordic countries, London: MacMillan Press, 1-27.

Sørensen, P. B. (2005), "Dual Income Taxation: Why and How?", FinanzArchiv: Public Finance Analysis, 61(4): 559-586.

Spearman, C. (1904), "The proof and measurement of association between two things", American Journal of Psychology, 15(1): 72-101.

Trivedi, P.K. and Zimmer, D. M. (2005), “Copula Modeling: An Introduction for Practitioners”, Foundations and Trends in Econometrics, 1: 1-111.

Wang, W. and Wells, M. T. (2000). "Model selection and semiparametric inference for bivariate failuretime data", Journal of the American Statistical Association, 95(449): 62-72. 


\section{Resumen}

El objetivo de este artículo es evaluar la inequidad horizontal (IH) causada por la introducción de una estructura (semi-) dual para el impuesto sobre la renta personal español (IRPF), usando funciones cópula para su medición. A partir de la metodología seguida por B $\varnothing$, Lambert and Thoresen (2012), se estiman las cópulas arquimedianas de Clayton, Frank y Gumbel para cuantificar el impacto sobre la IH de la reforma del IRPF de 2007, comparándolo con el correspondiente al diseño previo de 2006. Para identificar posibles efectos de anticipación y adaptación a la reforma, el análisis se extiende al periodo 2004-2010. En la investigación se han empleado los microdatos correspondientes al Panel de Declarantes de IRPF del Instituto de Estudios Fiscales. Los resultados obtenidos revelan dos efectos de la reforma sobre la IH, en dirección opuesta: mientras la división de la base imponible en dos bases (una gravada a un tipo proporcional) aumenta la $\mathrm{IH}$, la transformación de los mínimos exentos personales y familiares en deducciones de la cuota, la reduce. El predominio de un efecto sobre el otro depende de la escala de equivalencia aplicada.

Palabras clave: impuesto dual sobre la renta, IRPF, equidad horizontal, funciones cópula, reranking.

Clasificación JEL: D31, D63, H31 